\title{
Why are some websites researched more than others? A review of research into the global top twenty
}

\author{
Mike Thelwall
}

How to cite this article:

Thelwall, Mike (2020). "Why are some websites researched more than others? A review of research into the global top twenty". El profesional de la información, v. 29, n. 1, e290101.

https://doi.org/10.3145/epi.2020.ene.01

Manuscript received on $28^{\text {th }}$ September 2019 Accepted on $15^{\text {th }}$ October 2019

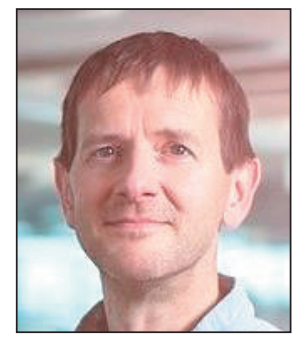

Mike Thelwall $\square$

https://orcid.org/0000-0001-6065-205X

University of Wolverhampton, Statistical

Cybermetrics Research Group

Wulfruna Street

Wolverhampton WV1 1LY, UK

m.thelwall@w/v.ac.uk

\begin{abstract}
The web is central to the work and social lives of a substantial fraction of the world's population, but the role of popular websites may not always be subject to academic scrutiny. This is a concern if social scientists are unable to understand an aspect of users' daily lives because one or more major websites have been ignored. To test whether popular websites may be ignored in academia, this article assesses the volume and citation impact of research mentioning any of twenty major websites. The results are consistent with the user geographic base affecting research interest and citation impact. In addition, site affordances that are useful for research also influence academic interest. Because of the latter factor, however, it is not possible to estimate the extent of academic knowledge about a site from the number of publications that mention it. Nevertheless, the virtual absence of international research about some globally important Chinese and Russian websites is a serious limitation for those seeking to understand reasons for their web success, the markets they serve or the users that spend time on them. The sites investigated were Google, YouTube, Facebook, Baidu, Wikipedia, QQ, Tmall, Taobao, Yahoo, Amazon, Twitter, Sohu, Live, VK, JD, Instagram, Sina, Weibo, Yandex, and 360.
\end{abstract}

\section{Keywords}

Webs; Major websites; Popular websites; Scholarly interest; Academic research; Success reasons; Comparative research; Cybermetrics; Google; YouTube; Facebook; Baidu; Wikipedia; Yahoo; Amazon; Twitter; Review article.

\section{Introduction}

The web is important source of information and communication for work, social and personal reasons. Social scientists therefore need to understand how it affects people's lives. For example, an inability to access websites can cause problems in richer nations (Dutton; Reisdorf, 2019), knowledge of usage patterns can help marketing initiatives (Mariani; Di-Felice; Mura, 2016), and investigations of social network sites are important to understand modern political movements (Bolsover; Howard, 2019). Websites offer many different affordances and it is important to investigate the most popular sites and genres so that their individual values can be known. Despite this, there are apparently no academic studies of the extent to which popular websites have been researched, a gap that the current paper addresses.

There have been previous reviews of internet-related research, especially in the early days of the web, finding that no academic discipline dominates it (Hunsinger, 2005; Silver, 2004), and the consequent lack of a systematic approach allows important sites to be ignored. An investigation of (online) social media research 2004-11 found it to be exponentially growing, with most articles originating from the USA (61\%) or UK (11\%) (Coursaris; Van-

Websites offer many different affordances and it is important to investigate the most popular sites and genres so that their individual values can be known 
Osch, 2014). A later study confirmed the exponential growth but, with different methods, found China to be second most productive country (Gupta; Dhawan; Gupta, 2015). There have also been reviews of social science research about individual websites, such as Facebook (Caers; De-Feyter; De-Couck; Stough; Vigna; Du-Bois, 2013), or an aspect of use of a website, such as health information on YouTube (Gabarrón; Fernández-Luque; Armayones; Lau, 2013) but there are not enough of these to be helpful for a systematic comparison of website research.

This article assesses whether globally popular websites have attracted substantial research interest, in terms of published journal articles related to them or mentioning them. The extent of academic interest in a website seems likely to be affected by a range of factors other than its overall popularity, however, and the following are hypothesised to be relevant: Country of use (popularity in countries that do not publish in international journals may lead to less research); Age (newer sites have had less time to be researched); provision of raw data for other purposes (such data increases the chance that a site is exploited for tangential research); novelty (more novel sites are more important to investigate), whether it contains user-generated data to investigate (Chi, 2008) and whether it supports activities within extensively researched areas. The citation impact of research about a website may also be an indicator of the extent to which the site is considered important within academia. Factors that may affect citation rates include country of use (since there are national differences in average citation impact) and website age (since newer websites have had less time for follow-up research about the site to cite earlier research about it).

\section{The content of Scopus-indexed research focusing on a top 20 website}

This section briefly reviews research into each of the top 20 websites in April 2019 (according to Alexa: Table 1; see the Methods for more details) published in Scopus-indexed journal articles. It focuses on research from a social science perspective that deals with affordances of the site for users, how the site is used, or characteristics of the site that are relevant to uses of it. Each section is mainly based on a search for the name of the site in Scopus-indexed journal article titles to restrict attention to research that has the site as a major focus or component. This section is not a traditional literature review in the sense of critically analysing the research covered. Instead, it attempts to characterise the scope of the papers. This gives insights into what has been researched but not how it was researched or what was discovered.

Table 1. Background information about Alexa.com's top 20 websites in April 2019.

\begin{tabular}{|c|c|c|c|c|}
\hline Rank & Site & Birth & Country & Type \\
\hline 1 & Google & 1998 & USA & Search, email, scholar, maps, others \\
\hline 2 & YouTube & 2005 & USA & Video sharing \\
\hline 3 & Facebook & 2004 & USA & Social network \\
\hline 4 & Baidu & 2000 & China & Search engine, email, maps, others \\
\hline 5 & Wikipedia & 2001 & USA & Encyclopaedia \\
\hline 6 & $Q Q$ & 1999 & China & Instant messaging \\
\hline 7 & Tmall & 2008 & China & Retail (B2C) \\
\hline 8 & Taobao & 2003 & China & Retail (C2C) \\
\hline 9 & Yahoo & 1994 & USA & Search, email, others \\
\hline 10 & Amazon & 1994 & USA & Bookstore, retail (B2C) \\
\hline 11 & Twitter & 2006 & USA & Microblog messaging \\
\hline 12 & Sohu & 1996 & China & Search, online gaming, others \\
\hline 13 & Live & 2005 & USA & Email, calendar, office software, others \\
\hline 14 & $V K$ & 2006 & Russia & Social network \\
\hline 15 & $J D$ & 1998 & China & Retail (B2C) \\
\hline 16 & Instagram & 2010 & USA & Photo sharing, video sharing \\
\hline 17 & Sina.com.cn & 1998 & China & Search, email, maps, others \\
\hline 18 & Weibo & 2009 & China & Microblog messaging \\
\hline 19 & Yandex & 1997 & Russia & Search, email, maps, others \\
\hline 20 & $360 . \mathrm{cn}$ & 2005 & China & Internet security, games, others \\
\hline
\end{tabular}




\section{Google}

Google is primarily known as a web search engine. There have been many studies of search engine user queries based on their search engine log files (Jansen; Spink; Saracevic, 2000) but none of these involved Google since it did not share its logs with researchers. The search behaviour of Google users has also been investigated, seeking to understand the search process (Lorigo; Pan; Hembrooke; Joachims; Granka; Gay, 2006). One article also analysed Google search output, seeking evidence of coverage or bias (Vaughan; Thelwall, 2004).

Many early papers also analysed the impact of Google on specific use contexts, such as library services (Norris, 2006), on the findability of online services (Ashmore; Gross, 2006), on specific types of user, such as deaf web users (Smith, 2006), or on specific information needs, including health-related (Pérez-López; Pérez-Roncero, 2006). Some research not focusing on Google searching nevertheless found it to be an important component of information behaviour, as in the example of an investigation into problem solving in a chemistry laboratory (Shultz; Zemke, 2019). Overall, however, since the web has become the default source for many types of information, there are many purposes and contexts for web searching and so it probably can never be fully understood. Nevertheless, most researchers are probably experienced users of Google and so detailed studies may be less important than they were in the early years of the search engine.

It seems unlikely that the volume of research reflects the volume of use; Gmail is probably far more widely used than Google Scholar

Google provides many services other than web search, including email, word processing, spreadsheets, discussion groups, academic search, image search and mapping. Each of these may generate dedicated bodies of social science research but this has not always occurred. For example, in April 2019 Scopus reported 341 journal articles containing the phrase "Google Earth" in their titles, compared to 248 for Google Scholar, 91 for Google Maps, 58 for Google Books, 29 for Google Docs, 13 for Google Drive, 11 for Gmail, and 1 for Google Photos. It seems unlikely that the volume of research reflects the volume of use; Gmail is probably far more widely used than Google Scholar. The case of Google Scholar is interesting because it fits well into the active research area of scientometrics by providing citation data (Bar-Ilan, 2008). Moreover, it provides a convenient source of data for analysis and so can be researched relatively quickly and cheaply, at least compared to standard Google searches. Thus, the volume of research about a service may be influenced by the pre-existence of academics with relevant expertise and the ease with which the service can be researched. In contrast, Gmail may be little researched because email is well understood and Google's offering is not fundamentally novel.

\section{YouTube}

There is a substantial body of research into aspects of YouTube culture, such as an analysis of Black women natural hair vloggers (Neil; Mbilishaka, 2019), factors that helped the Ice Bucket Challenge to spread virally (Kwon, 2019), YouTube commenting (Murthy; Sharma, 2019; Thelwall; Sud; Vis, 2012) and Mexican protest songs (corridos) as an alternative collective memory about traumatic events (Castillo-González; Leetoy, 2019). The specificity of these examples nevertheless suggests that their results would not generalise easily and that YouTube cultures may be too varied to be investigated systematically.

YouTube is also used by social scientists as a source of public evidence about a topic, even though the site itself is not relevant to the enquiry. For example, teams have investigated parents' video reactions to their children's autism diagnosis (Lloyd; Osborne; Reed, 2019), family reactions to being affected by the opioid crisis in the US (Johnson; Worth; Brookover, 2019), and squirrel videos to help understand their behaviour (Jagiello; Dyderski; Dylewski, 2019). Many articles are also hybrid, discussing the YouTube aspect of a wider issue, such as the representation of medical aspects of gender transformation (Miller, 2019).

There are many investigations into the quality of health information on YouTube, concerned that patients may find misleading information. Topics covered include disc herniation (Gokcen; Gumussuyu, 2019), prostate cancer (Loeb et al., 2019), premature ejaculation (Kaynak; Kaya; Aykaç, in press) and facelifts (Derakhshan; Lee; Bhama; Barbarite; Shaye, 2019). YouTube may be important for health information for users that prefer an explanation from a person to reading (for example) an encyclopaedia article.

The value of YouTube in support of formal education has been recognised in many disciplines. These include dance (lannone, 2019), science (Thelwall; Mas-Bleda, 2018) and clinical medicine (Rangarajan; Begg; Somani, 2019). Its support for research has also been assessed (Kousha; Thelwall; Abdoli, 2012).

The business, economics, politics or law of YouTube has been studied, including its international cultural adaptation strategies (Mohan; Punathambekar, 2019), the

The specificity of these examples nevertheless suggests that their results would not generalise easily and that YouTube cultures may be too varied to be investigated systematically 
effectiveness of vlogger brand endorsements (Munnukka; Maity; Reinikainen; Luoma-aho, 2019; Xiao; Wang; Chan-Olmsted, 2018), social media advertising strategies (Feng; Xie, 2019), political advertisements (Sohal; Kaur, 2018), reactions to Russian political events (Ushkin, 2014) and Russia Today's YouTube programming strategy (Orttung; Nelson, 2019).

\section{Facebook}

Facebook has been extensively researched since its academic beginnings. It was preceded by Friendster and MySpace, which were arguably more novel social network sites, but it has become more successful and eclipsed both in popularity. Social science Facebook research seems to typically investigate why and how (Chen; Kuo; Hsieh, 2019) people or organisations (Lam; Au; Chiu, 2019) use the site in many different educational, or social contexts. Other types of use are also investigated, such as politics (Yuan; Feng; Liu, 2019). Thus, Facebook seems to be particularly well researched in academia, at least from a social sciences perspective. This may be because it is frequently used by academics and its communications are relatively open (in comparison to email) and rich (in comparison to Twitter).

\section{Baidu}

The Baidu website, which is mainly known for its web search engine, is mentioned in only 11 Scopus-indexed social science journal article titles. Five used the Baidu Index tool that reports the volume of Baidu searches for a given keyword to track interest in topics through user searches, such as AIDS in China (Li et al., 2019). Another analysed the construction of pages in Baidu Baike, which is a Chinese version of Wikipedia (Cheng; Dong, 2018). Three papers compared Baidu to Google in terms of results or political background (e.g., Jiang, 2014) and two were about legal issues (e.g., Zhang, 2011). There seems to be no research in Scopus focusing on how people use Baidu searches, and only two articles investigating the processes behind the construction or use of Baidu Baike (Cheng; Dong, 2018; Wang; Sun; Shen; Zhang, 2018).

Presumably there are also many relevant Chinese-language articles that are not in Scopus.

\section{Wikipedia}

Wikipedia has been discussed for the new way in which it creates and disseminates knowledge (Hartelius, 2010) as well as for issues relating to the creation and maintenance of high quality content (Hara; Shachaf; Hew, 2010), including sources of references (Rodríguez-Mateos; Hernández-Pérez, 2018), and the motivations of its volunteers (Yang; Lai, 2010). The lack of female contributors has been a topic of concern (Ford; Wajcman, 2017). Wikipedia has generated issues for education, as a potential teaching resource (Moy; Locke; Coppola; McNeil, 2010; Vetter; McDowell; Stewart, 2019) as well as for the accuracy of its content as well as for referencing issues in assignments: the importance of primary sources and the credibility of editable information sources (Rand, 2010).

The content of Wikipedia is also sometimes analysed from an accuracy perspective, similarly to YouTube. Medical research, for example, has examined the accuracy of relevant Wikipedia pages, on the assumption that they are likely to be consulted by patients (Leithner et al., 2010; Simpson; Le; Malicka, 2018). WikiProject Medicine within Wikipedia is a related project to ensure the accuracy of medical pages (Heilman et al., 2011). Some articles have also assessed evidence for political or gender bias (Gauthier; Sawchuk, 2017; Stahel, 2018), or discussed potential coverage gaps (Luyt, 2018; Thelwall; Sud, 2018).

In addition to the potential educational and health information values of Wikipedia, it has also been discussed to understand its role as an open access intermediary, conveying scientific information to the public (Minguillón; Lerga; Aibar; Lladós-Masllorens; Meseguer-Artola, 2017; Teplitskiy; Lu; Duede, 2017).

Wikipedia is also extensively used as a knowledge resource for natural language processing applications (Azad; Deepak, 2019; Ray; Singh; Joshi, 2010), which is peripheral to user issues, and is sometimes assessed as a source of citation impact evidence (Kousha; Thelwall, 2017; Pooladian; Borrego, 2017; Thelwall, 2016).

A few studies have analysed aspects of Wikipedia use. One analysed temporal trends in searching, showing that external events trigger increases in relevant search volumes (Geiß; Leidecker; Roessing, 2016; Segev; Sharon, 2017). Another compared male and female student use of the site in Spain, finding that both genders used it equally, but males were less critical of its content (Obregón-Sierra; González-Fernández, 2019). Student perceptions of the value of Wikipedia for education have also been surveyed on a small scale (Blikstad-Balas, 2016; Cummings; DiLauro, 2017). The perspective of users outside of education concerning Wikipedia has largely been ignored, however, except in terms of news-related searches. 


\section{QQ}

Two articles have investigated use contexts for Tencent $Q Q$ instant messaging: factors associating with knowledge sharing in groups (Yuan; Liu, 2017) and reasons why students may use it to support their learning (Ma; Au, 2014). The marketing effectiveness of the site and its business model viability have also been investigated (Huang; Kim; Kim, 2013), as have users' privacy concerns (Meng; Zuo, 2008). Whilst this is a small set of articles, they are insightful for the user perspective.

\section{Tmall}

Only three Scopus-indexed journal articles mention Tmall in their titles, none of which focus on the site itself.

\section{Taobao}

The e-commerce site Taobao is the subject of a small number (38 Scopus title search matches) of insightful Scopus-indexed journal articles that investigate aspects of its use. For example, one paper analyses the Taobao villages phenomenon, which involves villages reorganising their production and distribution to make commodities for sale through the site (Qi; Zheng; Guo, 2019). Another investigates factors affecting consumer reluctance to trust the site (Han; Kim, 2017). Other articles also exploit data from the site to investigate economic models or theories, such as returns policies that optimise profits (Zhou; Hinz, 2016).

\section{Yahoo}

The role of the news services offered by Yahoo has been analysed from a business perspective for insights into its market niche (Li, 2017) or business model (Rindova; Yeow; Martins; Faraj, 2012). and aspects of its internal business processes have also been investigated (Matsuo, 2015; Pathak; Bathini; Kandathil, 2015). Early research investigated the topics that users searched for (Segev; Ahituv, 2010) and the directory system used by Yahoo to organise web pages (Callery; Proulx, 1997). The accuracy of the answers given on Yahoo Answers has been assessed for medical topics (Ohigashi et al., 2017), as discussed above for YouTube and Wikipedia. In contrast, music-related answers have been investigated from an information behaviour perspective, focusing on the types of questions asked and

The perspective of users outside of education concerning Wikipedia has largely been ignored, however, except in terms of news-related searches the types of answers given (Hertzum; Borlund, 2017). Also in contrast, the knowledge present in Yahoo Answers has been analysed from a Wikipedia-like perspective (Shen; Li; Liu; Grant, 2015). Political issues related to Yahoo in China have also been discussed (Stevens; Xie; Peng, 2016).

Yahoo is also used as a data source for natural language processing and related research (Figueroa; Gómez-Pantoja; Neumann, 2019; Olivares; Vivanco; Figueroa, 2018), and has been used for scientometric impact analysis (Zahedi; Shirazi; Dehghani, 2010).

\section{Amazon}

The core functions and economic model of Amazon have been topics of investigation. The usefulness of Amazon reviews for consumer purchases has been analysed (Chi, 2008; Lee; Trimi; Yang, 2018), as have aspects of its business model (Hadgkiss; Morris; Paget, 2019; Ritala; Golnam; Wegmann, 2014; Zhu; Liu, 2018) and legal issues (Rühl, 2018). Its recommender system technology is important to the site and has wider commercial value (Smith; Linden, 2017). Other than indirectly through purchase decisions, however, the user perspective has been mostly ignored for Amazon. com. One topic-limited and indirect exception is a study of reactions in Goodreads.com to its takeover by Amazon.com (Albrechtslund, 2017).

The Amazon.com website is also sometimes used as a convenient source of data to test marketing theories, such as the efficacy of convenience pricing online (Chenavaz; Drouard; Escobar; Karoubi, 2018). The Mechanical Turk environment for recruiting cheap labour has been exploited by many academic papers as a tool for research, and its value has also been analysed in a meta-study (Berinsky; Huber; Lenz, 2012).

\section{Twitter}

The role of Twitter as a news source has been examined from multiple perspectives, including perceived credibility of sources (Edgerly; Vraga, 2019), cross-cultural information flows (Mao; Menchen-Trevino, 2019) interaction with news channels (Ackland; O’Neil; Park, 2019) and agenda setting for the mainstream media (Quinn; Prendergast; Galvin, 2019). Sports news has also been investigated, for example analysing gender bias in official sports team accounts (Grace; Mueller, 2019). Perhaps also related to news coverage, politics is widely discussed on Twitter and investigated (O'Boyle, 2019), including for evidence of the partisanship and bias of journalists (Lacatus, 2019; Usher; Holcomb; Littman, 2018). Social campaigns, such as the \#MeToo movement, have also been investigated (Xiong; Cho; Boatwright, 2019).

Various ways of exploiting Twitter in education have been proposed and evaluated (Luo; Xie, 2019; Ober, 2019). Twitter-based marketing campaigns have also been evaluated, including an international comparison of alcoholic drinks (Gupta; Lam; Pettigrew; Tait, 2019). 
Twitter has also been used as a convenient source of public opinion information by researchers that are not interested in the site itself. For example, cycling-related tweets reveal information about cyclists' motivations (Das; Dutta; Medina; Minjares-Kyle; Elgart, 2019), tweets about a walking trail might reveal problems with parts of it (Wilson; Lovelace; Evans, 2019), and tweets about a tobacco product may reveal how users react to it (Malik; Li; Karbasian; Hamari; Johri, 2019).

The usage patterns of groups have been investigated in Twitter, including teachers (Carpenter; Kimmons; Short; Clements; Staples, 2019), politicians (Spierings; Jacobs; Linders, 2019), journalists (Tandoc; Cabañes; Cayabyab, 2019), and non-profit organisations (Dong; Rim, 2019).

Overall, social science Twitter research seems to investigate many different types of user and use. Reflecting the widespread use of Twitter in social science research, there are also methodological articles on effective sampling of tweets (Hino; Fahey, 2019) and biases in Twitter samples (Jiang; Li; Ye, 2019). Twitter research seems therefore to be highly developed. This may be due to the ease of access of tweets through a free public applications programming interface, its widespread use, and, presumably, the familiarity of many Western researchers with it.

\section{Sohu}

Three Scopus-indexed journal articles mention search and online gaming site Sohu in their titles but none focus on the site.

\section{Live.com}

No Scopus-indexed journal articles mention search and services portal Live.com in their titles.

\section{VK}

Research on the Russian VKontakte social network seems to broadly follow Facebook research in topic, but is much rarer and mostly available in Russian. For example, one paper (with only the abstract in English) analysed a Bhuddist VK discussion group (Badmatsyrenov; Skvortsov; Khandarov, 2018) and another analysed discussion of a terrorist attack in Romania on the site (Barabash; Bobryshova; Lepilkina; Karabulatova, 2018), and another investigated self-presentation in the site (Shchekoturov, 2017). VK data has also been used to map HIV networks (Rykov; Koltsova; Meylakhs, 2016) and teenage interests (Polivanova; Smirnov, 2017).

\section{JD.com}

One journal article focuses on Amazon-like retail site JD.com, analysing the quality of its reviews, and proposing a system to automatically classify this (Liu; Fu; Liu; Sun, in press).

\section{Instagram}

As relevant to an image-based site, much Instagram research addresses visual aspects through either qualitative or quantitative methods. Self-presentation strategies are a common theme (Yau; Reich, 2019), including the relationship between posts and body image (Baker; Ferszt; Breines, 2019) and special groups, such as female body builders (Marshall; Chamberlain; Hodgetts, 2019) and American skateboarders (Dupont, in press). The role of Instagram in aspects of everyday lives has been addressed through user attitudes towards current and potential future romantic partners (Lee; Choi; Lee; Sung, 2019), coping with cancer (Stage, 2019) and promoting healthy behaviours (Santarossa; Coyne; Lisinski; Woodruff, 2019). User reactions to viewing Instagram posts have also been analysed from the perspective of the emotions generated (De-Vries; Möller; Wieringa; Eigenraam; Hamelink, 2018).

Influential sets of pictures have also been examined, such as one from North Korea (Holiday; Anderson; Lewis; Nielsen, 2019), and dieticians' food photograms (Inan-Eroglu; Buyuktuncer, 2018).

Marketing is important for Instagram, as for YouTube, because of its novel affordances. Issues covered include the effectiveness of influencers in promoting brands (De-Veirman; Hudders, 2019; Konstantopoulou; Rizomyliotis; Konstantoulaki; Badahdah, 2018) and visual marketing strategies used in the site (Laestadius; Wahl; Pokhrel; Cho, 2019). Individual market segments have also been addressed, such as tourism (Kuhzady; Ghasemi, 2019) and television (Martín-Quevedo; Fernández-Gómez; Segado-Boj, 2019).

Overall, Instagram seems to have been extensively researched from various user perspectives as well as for marketing.

\section{Sina.com.cn}

No Scopus-indexed journal articles mention sina.com.cn and none seem to mention the Sina web company (except in the context of Sina Weibo) in their titles.

\section{Weibo}

The potential for Weibo to promote healthy behaviours has been investigated, such as through posting fitness information from electronic devices (Dong; Chen; Wang, 2019) and by identifying the factors that help health messages to be shared virally (Liu; Lu; Wang, 2017). It has also been investigated for its ability to facilitate social support for people with long-term illnesses (Han; Li; Qu; Zhu, 2018). 
Politics has also been analysed, such as by identifying ideological positions expressed through weibos (Huang; Gui; Sun, 2019), international differences in the framing of news discussions (Bolsover, 2017), public discussion of "Brother Wristwatch" 表哥, a corrupt safety official caught out on Weibo from crowdsourced images of him wearing expensive watches (Feng; $\mathbf{W u}, 2018)$, how discontent with some government actions is expressed (Wu, 2018), government censorship of the site (Cairns; Carlson, 2016; Vuori; Paltemaa, 2015), and how it can facilitate political involvement for college students (Wang; Shi, 2018).

Weibo is used for brand marketing and therefore it is important to analyse commercial strategies, including from linguistic (Li; Wu, 2018) comparative (Wen; Clark; Kang; Fine, 2016) perspectives. Other use cases examined include librarianship through a comparison with Twitter (Huang; Chu; Liu; Zheng, 2017), journalist posting strategies (Fu; Lee, 2016), information dissemination by non-government organisations (Zhou; Pan, 2016), rural migrant workers' posts (Zhang, 2013) and the effectiveness of Weibo for crisis communication (Ngai; Jin, 2016).

Like Twitter, Weibo has been used as a convenient source of public sentiments about topics unrelated to the site, such as green buildings (Liu; Hu, 2019) and tourist opinions about attractions (McCartney; Pek, 2018). It has also been used for information about the external environment, such as through reports about air quality and pollution (Graminius; Haider, 2018), and as a natural language processing resource (Ling; Marujo; Dyer; Black; Trancoso, 2016).

As with Wikipedia and Twitter, Weibo has been used as a source of evidence about the impact of academic research and the extent to which science is discussed (Yu; Xu; Xiao; Hemminger; Yang, 2017).

Weibo has also been investigated from a more general perspective to understand how discussion topics evolve in the site, and how this contrasts with Twitter (An; Yu; Lin; Du; Zhou; Li, 2018).

Many of the above studies have analysed aspects of the user experience on Weibo, users have also been surveyed to find out which benefits they believe they get from it (Gan, 2018), how users may be anxious about their posts (Li; Lin, 2016) and privacy and anonymity conditions have been investigated (Chen; Li; Hu; Li, 2016). Overall, therefore, there is a rich and diverse academic literature about Sina Weibo.

\section{Yandex}

No Scopus-indexed journal articles mention Russian search engine Yandex in their titles. Like Google, Yandex offers a range of services from email to maps.

\section{0.cn}

No Scopus-indexed journal articles mention Chinese internet security and games site 360.cn in their titles. None of the matches of the search for 360 seem to be about the site either. This seems to be a background service that many not be directly mentioned in research that uses it.

\section{Summary}

The amount of Scopus-indexed research mentioning the top 20 websites in article titles is highly variable, from extensive coverage of Facebook, Twitter, YouTube and Weibo to no research focusing on Yandex and 360.cn. Part of the difference is likely to be due to language (because Scopus is dominated by English) and first mover (the first popular website of a type should attract the most attention due to novelty) issues. In addition, some websites have opportunities for substantial user content generation, e.g., Facebook, Twitter, YouTube, Weibo but not Google, Yandex, 360.cn. Also, more flexible sites seem to attract more attention than those with a single activity focus, such as Tmall and Taobao.

Whilst sites that are flexible in use and allow user content generation have attracted the most research, typically from the social sciences investigating social issues, usage patterns or commerce, it seems likely that this research is far from comprehensive. For example, whilst there is a large volume of research covering multiple aspects of YouTube, it seems likely issues relevant to YouTube are too complex to be analysed with any degree of completeness. Similarly, it seems likely that academia could investigate only a small fraction of Facebook uses because it is a flexible community site. This is exacerbated for Facebook by its default privacy policy so that user behaviours are typically hidden. Thus, paradoxically, the sites that are most researched may also have the most scope for further research into other aspects of their use.

\section{Methods}

The above section briefly reviewed research with a major focus on a top 20 website, using the heuristic of mentioning the site in the title. The reminder of the article is a bibliometric analysis of the prevalence and citation impact of articles that mention these websites in their abstract, keywords or title. This wider scope allows an analysis of the influence of the sites on research, a different focus.
The amount of Scopus-indexed research mentioning the top 20 websites in article titles is highly variable, from extensive coverage of Facebook, Twitter, YouTube and Weibo to no research focusing on Yandex and 360.cn 
The top 20 of the Alexa.com top 500 global websites list in April 2019 was used as the source of popular websites. https://www.alexa.com/topsites

Alexa.com uses a range of sources of evidence, including browser extensions and website scripts, to estimate the number of visitors to major websites over the previous three months, https://www.alexa.com/about

The exact sources of data and algorithm combining them are commercial secrets but the site has credibility through its owner, Amazon, its long history (since 1996) and prior use in academic research (e.g., Han; Kim, 2017; Lui, 2015; Vaughan, 2012). Nevertheless, its traffic data should be treated as estimates rather than precise values. In addition, it is not clear how it deals with web traffic through smartphone apps rather than web browsers and it does not adequately rank popular internet services that do not primarily operate through their websites, such as WhatsApp. Another limitation for the current study is that the figures do not consider whether a website is relatively new and cannot therefore have had much research published with it.

The Scopus citation index was used to estimate the prevalence and citation impact of international research about the chosen websites. Scopus was used in preference to the Web of Science because it has wider coverage, and particularly for non-English and non-Western sources (Mongeon; Paul-Hus, 2016). Scopus queries were used to identify articles mentioning one of the top 20 websites. Since the websites could be mentioned peripherally in the full text of an article, the queries were restricted to the parts of an article that normally signal its core content: the title, abstract and keywords. The queries were tested and modified when they produced a high proportion of false matches, as in the case of $Q Q$, Live, $V K, J D$, and Sina (Table 2). There were a few ornithology matches for Twitter (about 2 per year) but this proportion is too low to greatly influence the results. The Russian name of VK (ВКонта́кme) produced only a single match and so its English translation was used. The Scopus queries were submitted on 18 April 2019. Documents not within academic journals were subsequently excluded, as were documents from before a website existed, or from after 2018 (for field normalisation purposes, as described below). The results are nevertheless limited by the comprehensiveness of the English-language queries used to identify relevant articles.

Table 2. The Scopus queries submitted on 18 April 2019 to identify articles mentioning one of Alexa's top 20 websites.

\begin{tabular}{|c|l|l|l|}
\hline Rank & \multicolumn{1}{|c|}{ Site } & \multicolumn{1}{c|}{ Query } & \\
\hline 1 & Google & Google & TITLE-ABS-KEY(Google) AND DOCTYPE(ar) \\
\hline 2 & YouTube & YouTube & TITLE-ABS-KEY(YouTube) AND DOCTYPE(ar) \\
\hline 3 & Facebook & Facebook & TITLE-ABS-KEY(Facebook) AND DOCTYPE(ar) \\
\hline 4 & Baidu & Baidu & TITLE-ABS-KEY(Baidu) AND DOCTYPE(ar) \\
\hline 5 & Wikipedia.org & Wikipedia & TITLE-ABS-KEY(Wikipedia) AND DOCTYPE(ar) \\
\hline 6 & QQ & Tencent QQ & TITLE-ABS-KEY(Tencent QQ) AND DOCTYPE(ar) \\
\hline 7 & Tmall & Tmall & TITLE-ABS-KEY(Tmall) AND DOCTYPE(ar) \\
\hline 8 & Taobao & Taobao & TITLE-ABS-KEY(Taobao) AND DOCTYPE(ar) \\
\hline 9 & Yahoo & Yahoo! & TITLE-ABS-KEY(Yahoo!) AND DOCTYPE(ar) \\
\hline 10 & Amazon & Amazon.com & TITLE-ABS-KEY(Amazon.com) AND DOCTYPE(ar) \\
\hline 11 & Twitter & Twitter & TITLE-ABS-KEY(Twitter) AND DOCTYPE(ar) \\
\hline 12 & Sohu & Sohu & TITLE-ABS-KEY(Sohu) AND DOCTYPE(ar) \\
\hline 13 & Live & live.com & TITLE-ABS-KEY(live.com) AND DOCTYPE(ar) \\
\hline 14 & VK & Vkontakte & TITLE-ABS-KEY(Vkontakte) AND DOCTYPE(ar) \\
\hline 15 & JD & jd.com & TITLE-ABS-KEY(jd.com) AND DOCTYPE(ar) \\
\hline 16 & Instagram & Instagram & TITLE-ABS-KEY(Instagram) AND DOCTYPE(ar) \\
\hline 17 & Sina.com.cn & sina.com.cn & TITLE-ABS-KEY(sina.com.cn) AND DOCTYPE(ar) \\
\hline 18 & Weibo & Weibo & TITLE-ABS-KEY(Weibo) AND DOCTYPE(ar) \\
\hline 19 & Yandex.ru & Yandex & TITLE-ABS-KEY(Yandex) AND DOCTYPE(ar) \\
\hline 20 & $360 . c n$ & $360 . c n$ & TITLE-ABS-KEY(360.cn) AND DOCTYPE(ar) \\
\hline & &
\end{tabular}

The Scopus citation count was extracted for each journal article and used to calculate the mean normalised log citation score (MNLCS) (Thelwall, 2017). This is a variant of the original mean normalised citation score (MNCS) (Waltman; VanEck; Van-Leeuwen; Visser; Van-Raan, 2011), using logged citation counts to stop small numbers of very highly cited articles unduly influencing the results. The MNLCS has a value of 1 if the articles tended to have the same number of citations as other articles from the same field and year. MNLCS values above 1 indicate more citations than the world average for the field and year of publication, and values below 1 correspond to below world average citation counts for 
the publishing field and year. When articles were recorded within multiple Scopus categories, the average (arithmetic mean) of all Scopus categories was used as the denominator.

\section{Results}

There are vastly different amounts of research relating to the top 20 websites (Figure 1), ranging from 16,362 for Google to 1 each for Sina and 360 . cn (both with complex queries). There is not a strong trend for sites with more research to also have higher impact research about them, however, with a weak Spearman correlation of only 0.247 between these two.

For websites mentioned by relatively many articles, there is a clear trend for the volume of research to increase over time (Figures 2 and 3). There is evidence of peaking or levelling off for Wikipedia, and Weibo, whe-

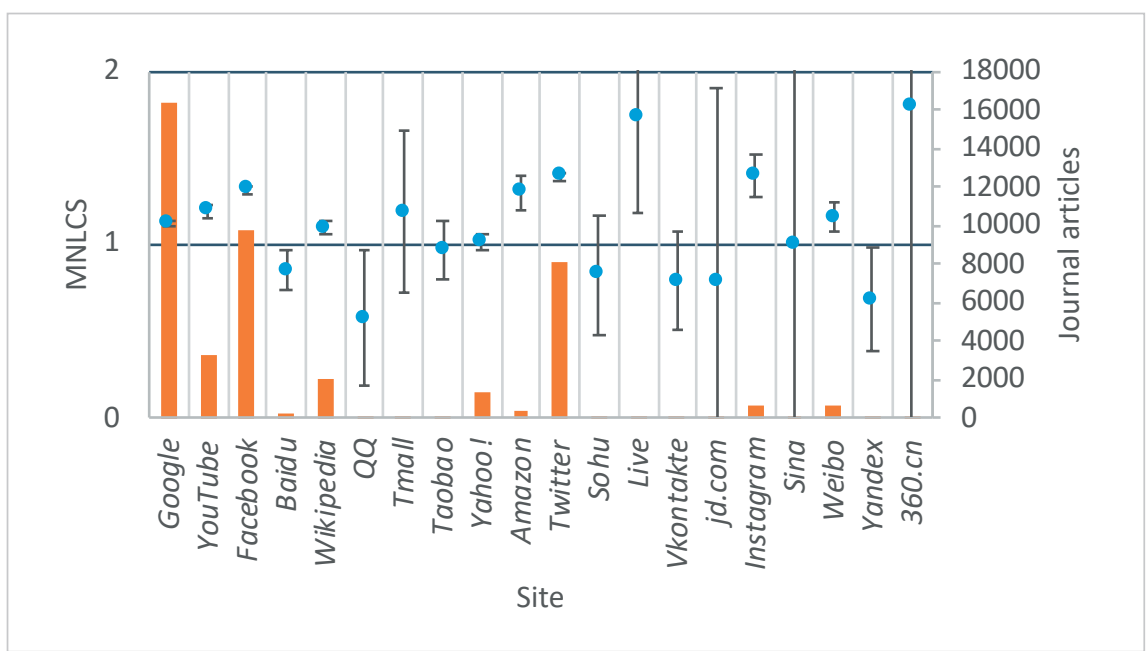

Figure 1. The number of Scopus-indexed journal articles 1996-2018 mentioning each website in their abstract, title or keywords (bars) and the MNLCS of these articles (dots with $95 \%$ confidence interval error bars). Websites are in decreasing order of popularity according to Alexa.com in April 2019. The world average MNLCS is 1 for all fields and years. reas Amazon has three years of decline before increasing again. Whilst research mentioning Google and Facebook is increasing rapidly, despite their age, it is no longer growing approximately exponentially.

Research about major websites usually has above world average citation impact (for its field and year) when the difference is statistically significant (Figure 2 and 3). The two main exceptions are that Yahoo research since 2002 and Wikipedia research since 2012 have had close to world average citation impact.

\section{Discussion}

Some of the global 20 most popular websites (according to Alexa.com) seem to have almost no journal articles closely related enough to them for a mention in the article title, abstract or keywords. Most of the websites with almost no Scopus-indexed research are from China (Tencent QQ, Tmall, Taobao, Sohu, JD, Sina, 360.cn) or Russia (VK, Yandex). There is a small amount of research about the Chinese site Baidu, but this is relatively low for its popularity. In contrast, Chinese site Weibo has a substantial amount of research and is therefore an anomaly for the language issue mentioned above. This anomaly is nevertheless in line with the high volume of Twitter-related research since both sites have similar affordances (an applications programming interface allowing automated access to content). Thus, overall, site nationality (Table 1) is enough to explain the low position of most of the sites. A similar issue has been observed within another repository of knowledge, Wikipedia, which has greater coverage of topics relevant to an English-speaking audience despite its international variants (Thelwall; Sud, 2018).

Whilst China is a major contributor to international academic output, its social science research is much less international (Liu; Hu; Tang; Wang, 2015), explaining the lack of Scopus-indexed research about Chinese websites. Scopus has weaker coverage of non-English research, particularly in the Social Sciences and Humanities (Mongeon; Paul-Hus, 2016), exacerbating the problem. China accounted for only 3.5\% of Social Sciences articles in Scopus and Russia accounted for $0.9 \%$ by April 2019 . Websites that are in Chinese or Russian therefore have two obstacles for researchers: relatively few researchers publishing international academic social science journal articles can read

There are vastly different amounts of research relating to the top 20 websites, ranging from 16,362 for Google to 1 each for Sina and 360.cn them and relatively few may know them well enough to consider them interesting or relevant. The problem may be further exacerbated by the non-English sites being referred to in different ways and being mainly known by their original Chinese or Russian names.

The website live.com is has little research that directly mentions it probably because it hosts services that are better known by other names, such as Microsoft OneDrive, Outlook and Office. This may also affect some of the Chinese websites. 

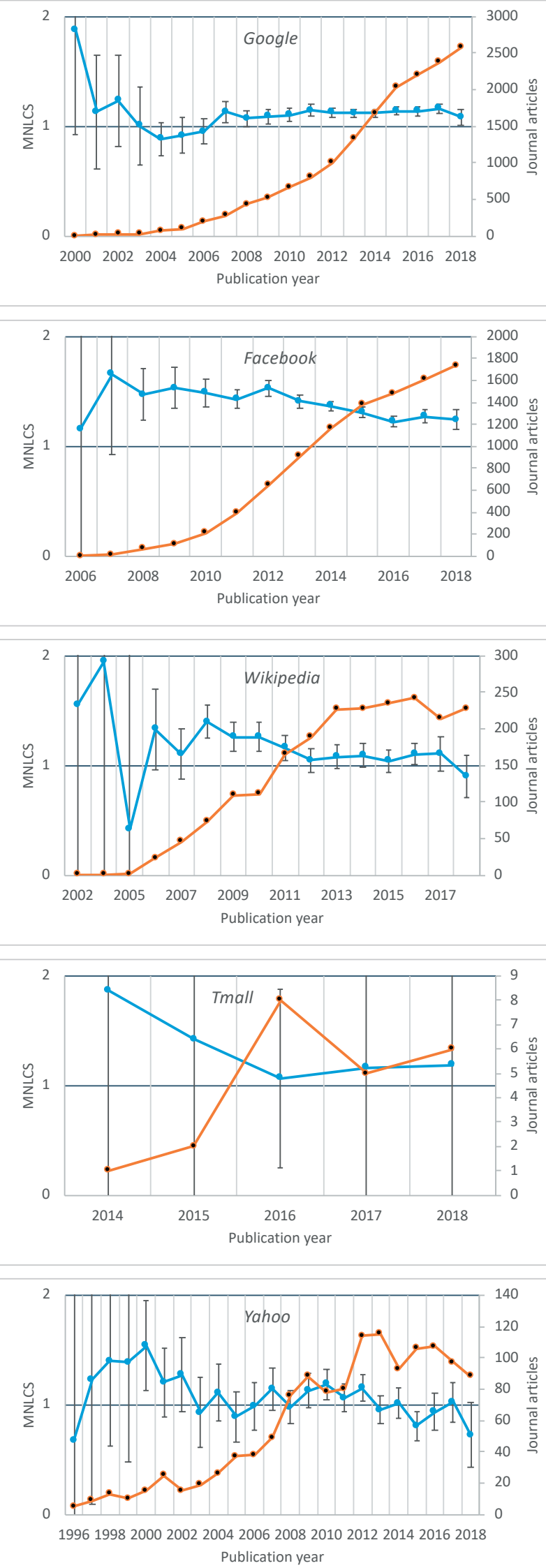
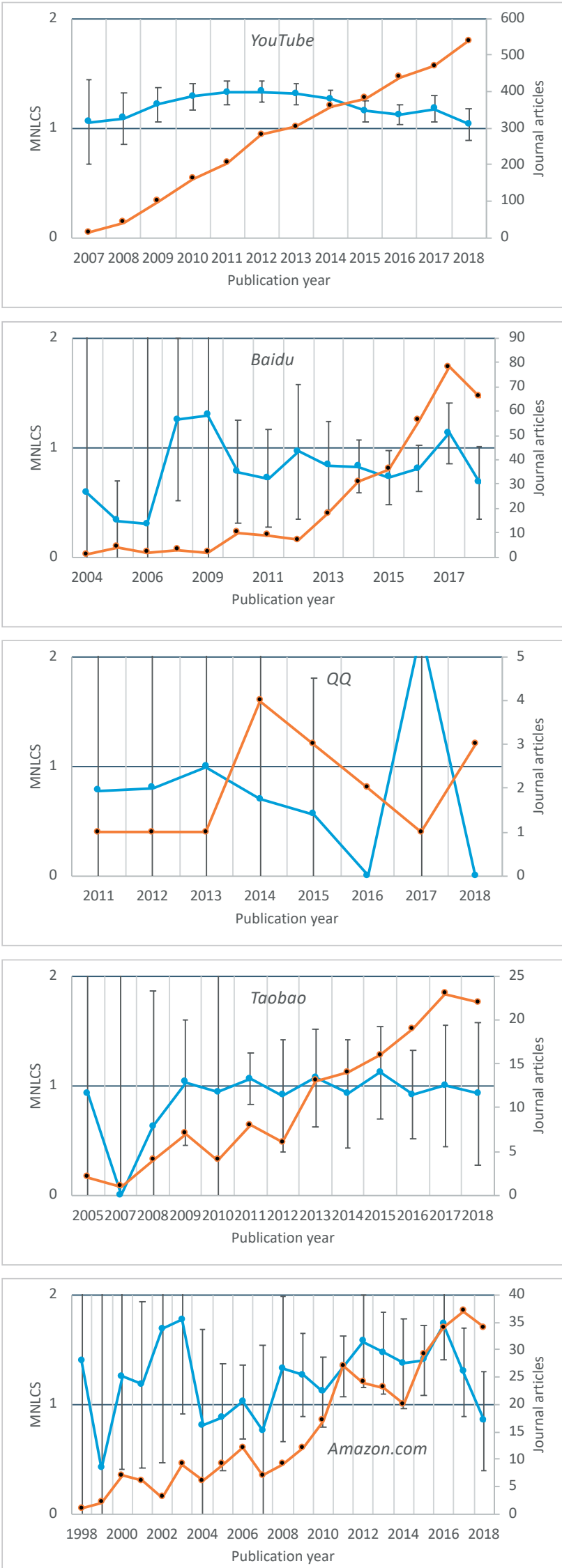

Figure 2. The number of Scopus-indexed journal articles 1996-2018 mentioning the specified website in their abstract, title or keywords (black dots) and the MNLCS of these articles (blue dots with 95\% confidence interval error bars). The websites are the most popular 10 according to Alexa.com in April 2019. 

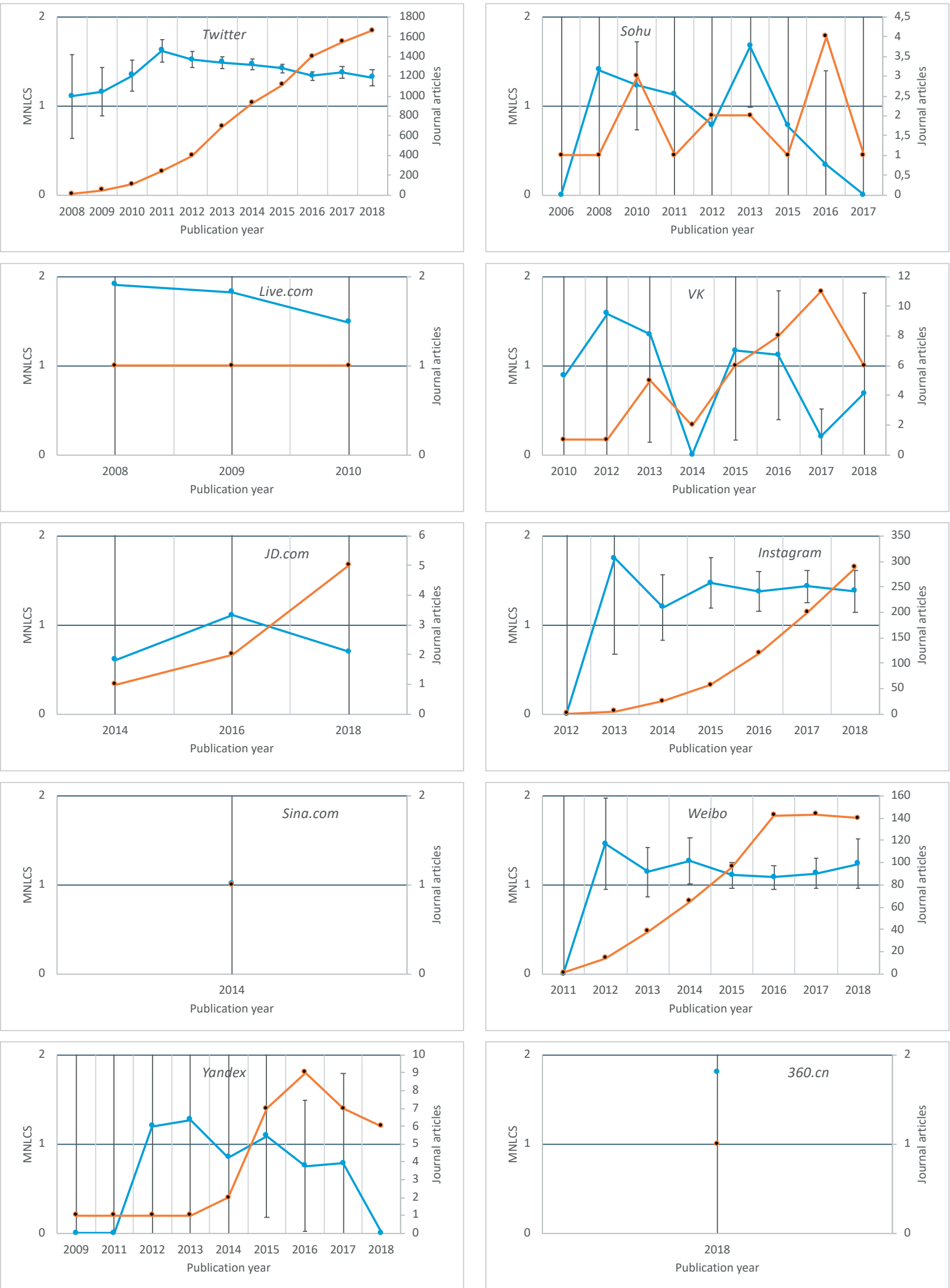

Figure 3. The number of Scopus-indexed journal articles 1996-2018 mentioning the specified website in their abstract, title or keywords (black dots) and the MNLCS of these articles (blue dots with 95\% confidence interval error bars). The websites are the most popular 11-20 according to Alexa.com in April 2019. 
Twitter and Weibo have a relatively large amount of research mentioning them. This may be because they can be easily used as a source of evidence (tweets, weibos) in text processing computer science or linguistics research. For example, $52 \%$ of Weibo and $46 \%$ of Twitter research in Scopus is classified as Computer Science or Mathematics. Each site is more extensively researched in its own country, with US first authors outnumbering mainland Chinese first authors by 6.2 to 1 for Twitter and mainland Chinese first authors outnumbering US first authors by 7.3 to 1 for Weibo.

Another anomaly in the graphs is that YouTube has about a third as much research as Facebook, despite Facebook being less popular. This could be explained by Facebook having been more popular than YouTube in the past. Another possible explanation is Facebook's origins within academia and, presumably, its academic-friendly affordances. In contrast, YouTube may be thought to be primarily an entertainment site, even though it is used in education (e.g., Barry et al., 2016). The greater flexibility of Facebook to be a site for organising groups and providing different types of information (including videos) is probably also a factor because it provides a wider variety of use types to investigate.

Of the factors considered in the introduction, website age does not seem to be relevant to explain the level of research interest in a top 20 website because all the sites are over ten years old and there is not a trend for newer sites to be discussed less, at least within this list. The novelty of a website is a possible explanatory factor given that the Chinese and Russian websites are slightly younger than similar sites from the USA, but it seems likely that the language or geography issue is more important.

The usefulness of Google's affordances for academic research methods help to explain the amount of research about it. Almost a third (31\%) of papers mentioning Google discuss Google Scholar, typically as a source of data for citation analysis or literature searches. Another $14 \%$ discuss Google Maps, typically using it as a tool in computing or geographical information systems research (e.g., "Timely reporting and interactive visualization of animal health and slaughterhouse surveillance data in Switzerland"). These studies give no social science insights into the use of Google. The same is true for some of the other sites. For example, 10\% of Amazon research uses its Mechanical Turk service and a few (12) YouTube articles only used a video dataset derived from it, "YouTube Action" or UCF11. Similarly, Facebook is used to recruit survey or interview participants around a focused topic, such as, "The psychosocial impact of ptosis as a symptom of myasthenia gravis: A qualitative study", or to track people, "Patients with outdated details were tracked with the national health insurance database and social media (Facebook)" (Kowalewski; Olszewski; Kwiatkowski; Gałązka-Świderek; Cichoń; Paśnik, 2017), although most Facebook research seems to investigate an aspect of the use of the site itself (e.g., "Connected motherhood: Social support for moms and moms-to-be on Facebook").

\section{Academic knowledge requirements}

Although the results show gaps in knowledge about important social web sites, the empirical data cannot prove that the gaps are important. It is impossible for academic research to generate all possible knowledge and so a useful consideration is whether the omissions will be a substantial disadvantage in practice. Site users, including businesses, can get information from other sources, including professional magazines, blogs, white papers, networks, and their own experience or analysis. Thus, a lack of academic knowledge does not imply that a site is being underexploited or poorly used. Apparently relatively straightforward sites, such as those for e-commerce, may not need much research to understand their fundamentals.

Research often serves educational uses so academic studies of websites may be less important when those websites are not relevant to degree courses. This may apply to the standard office services offered by Live.com and within other websites (e.g., email from Google, Yandex, Sina, Baidu). Thus, part of the issue is whether academic research is the most relevant avenue for publishing research about popular websites.

Despite the above consideration, the lack of knowledge is not a guarantee that a topic is unimportant. The case of neglected tropical diseases (Hotez et al., 2007; Mathers; Ezzati; López, 2007) is a well-known example of a knowledge area that is recognised as being under-researched for its societal importance. Thus, the current paper can identify research gaps but qualitative judgements are needed to assess whether the gaps are important.

\section{Citation impact}

Research related to top websites seems to usually have above average citation impact, except that there is a (not statistically significant) trend for the Chinese and Russian sites to have below world average citation impact or, in the case of Weibo, lower citation impact than the similar site Twitter. This is probably due to research in these countries having lower overall average citation impact (Elsevier, 2013; Fairclough; Thelwall, 2015) rather than being a characteristic of the studies. Nevertheless, the lower citation impact, and the dominance of Western sites in international research, may serve as a disincentive for researchers seeking international recognition to study Chinese and Russian sites. 


\section{Conclusions}

This study found vastly different levels of academic publishing related to the globally most popular twenty websites (according to Alexa.com). The main reason for differences in the amount of research about a site seems to be the following.

- Less research for non-English websites. Generalising this, there is likely to be even less research about non-English websites serving an area with few social science researchers publishing in English. Such research may be available in local language journals (where it may be most useful and most read) but seems unlikely to be visible to an international audience.

- Less research for websites that host services rather than being primary portals.

- More research about flexible sites that can be adapted for different social purposes, such as organising groups, disseminating information, or communicating with friends.

- More research about websites that provide an easily accessible source of data for computing-related research. Because of this, even if a website is important enough to be mentioned in an article title, abstract or keywords, the article's findings may reveal nothing about the site.

- More research about websites that provide affordances for research methods. As above, this type of research may not be informative about the site itself.

Thus, the level of academic interest in a website does not accurately reflect its global importance from a social science perspective or the depth of academic knowledge about it.

Despite the limitations of the methods, the results give evidence that several globally important non-US websites are mostly receiving little international research attention. This is a problem for developers seeking to understand the factors behind the success of individual websites, for marketers needing information about the role in the information, entertainment and retail infrastructures of the audiences that they serve, and for social scientists wanting deeper international insights into how users interact with websites for aspects of their daily lives (e.g., health, socialising, media consumption). Thus, there is a need for more international comparative research into popular websites as well as studies that focus on international websites. Even though such research may have lower citation impact, editors and reviewers should be aware of this important gap when evaluating the contribution of such papers.

There is a need for more international comparative research into popular websites as well as studies that focus on international websites

\section{References}

Ackland, Robert; O'Neil, Mathieu; Park, Sora (2019). “Engagement with news on Twitter: insights from Australia and Korea". Asian journal of communication, v. 29, n. 3, pp. 235-251.

https://doi.org/10.1080/01292986.2018.1462393

Albrechtslund, Anne-Mette-Bech (2017). "Negotiating ownership and agency in social media: Community reactions to Amazon's acquisition of Goodreads". First Monday, v. 22, n. 5. https://firstmonday.org/ojs/index.php/fm/article/view/7095/6161

An, Lu; Yu, Chuanming; Lin, Xia; Du, Tingyao Zhou, Liqin; Li, Gang (2018). "Topical evolution patterns and temporal trends of microblogs on public health emergencies: An exploratory study of Ebola on Twitter and Weibo". Online information review, v. 42, n. 6, pp. 821-846.

https://doi.org/10.1108/OIR-04-2016-0100

Ashmore, Beth; Gross, Jill E. (2006). “Google and OCLC open libraries on the open web". Searcher, v. 14, n. 10, pp. 44-52.

Azad, Hiteshwar-Kumar; Deepak, Akshay (2019). "A new approach for query expansion using Wikipedia and WordNet". Information sciences, v. 492, n. 1, pp. 147-163.

https://doi.org/10.1016/j.ins.2019.04.019

Badmatsyrenov, Timur B.; Skvortsov, Maxim V.; Khandarov, Fedor V. (2018). "Buddhist digital practices of transcendence: VK-community 'Hambo Lama Dashi-Dorzho Itigilov'. Мониторинг общественного мнения: экономические и социальные перемены (Monitoring Obshchestvennogo)". Monitoring of public opinion: Economic and social changes, v. 144, n. 2, pp. 309-332.

https://doi.org/10.14515/monitoring.2018.2.18

Baker, Nicole; Ferszt, Ginette; Breines, Juliana G. (2019). “A qualitative study exploring female college students' Instagram use and body image". Cyberpsychology, behavior, and social networking, v. 22, n. 4, pp. 277-282. https://doi.org/10.1089/cyber.2018.0420

Bar-Ilan, Judit (2008). "Which h-index? - A comparison of WoS, Scopus and Google Scholar". Scientometrics, v. 74, n. 2, pp. 257-271.

https://doi.org/10.1007/s11192-008-0216-y 
Barabash, Viktor V.; Bobryshova, Aleksandra S.; Lepilkina, Olga I.; Karabulatova, Irina S. (2018). "The specific of the interpretation of tragedy over Sinay (October 31, 2015) as a focus of information attention of the 'Vkontakte' social network". Astra salvensis, v. 6, n. 11, pp. 289-310.

https://www.ceeol.com/search/article-detail?id=666884

Barry, Denis S.; Marzouk, Fadi; Chulak-Oglu, Kyrylo; Bennett, Deidre; Tierney, Paul; O’Keeffe, Gerard W. (2016). “Anatomy education for the YouTube generation". Anatomical sciences education, v. 9, n. 1, pp. 90-96.

https://doi.org/10.1002/ase.1550

Berinsky, Adam J.; Huber, Gregory A.; Lenz, Gabriel S. (2012). "Evaluating online labor markets for experimental research: Amazon.com's Mechanical Turk". Political analysis, v. 20, n. 3, pp. 351-368.

https://doi.org/10.1093/pan/mpr057

Blikstad-Balas, Marte (2016). "'You get what you need': A study of students' attitudes towards using Wikipedia when doing school assignments". Scandinavian journal of educational research, v. 60, n. 6, pp. 594-608.

https://doi.org/10.1080/00313831.2015.1066428

Bolsover, Gillian (2017). "Harmonious communitarianism or a rational public sphere: a content analysis of the differences between comments on news stories on Weibo and Facebook". Asian journal of communication, v. 27, n. 2, pp. 115-133.

https://doi.org/10.1080/01292986.2016.1214743

Bolsover, Gillian; Howard, Philip (2019). “Chinese computational propaganda: automation, algorithms and the manipulation of information about Chinese politics on Twitter and Weibo". Information, communication \& society, v. 22, n. 14, pp. 2063-2080.

https://doi.org/10.1080/1369118X.2018.1476576

Caers, Ralf; De-Feyter, Tim; De-Couck, Maijke; Stough, Talia; Vigna, Claudia; Du-Bois, Cind (2013). “Facebook: A literature review". New media \& society, v. 15, n. 6, pp. 982-1002.

https://doi.org/10.1177/1461444813488061

Cairns, Christopher; Carlson, Allen (2016). "Real-world islands in a social media sea: Nationalism and censorship on Weibo during the 2012 Diaoyu/Senkaku crisis". The China quarterly, v. 225, n. 1, pp. 23-49.

https://doi.org/10.1017/S0305741015001708

Callery, Anne; Proulx, Den-Tracy (1997). “Yahoo! cataloging the web”. Journal of internet cataloging, v. 1, n. 1, pp. $57-64$. https://doi.org/10.1300/J141v01n01_06

Carpenter, Jeffrey P.; Kimmons, Royce; Short, Cecil R.; Clements, Kyle; Staples, McKenzie-Emmet (2019). "Teacher identity and crossing the professional-personal divide on Twitter". Teaching and teacher education, v. 81, pp. 1-12.

https://doi.org/10.1016/j.tate.2019.01.011

Castillo-González, María-Concepción; Leetoy, Salvador (2019). "The Mexican corrido in the age of YouTube: Collective memory, cultural agency and hybridisation in the Ayotzinapa case". Comunicacion y sociedad, e6997, 1-27.

https://doi.org/10.32870/cys.v2019i0.6997

Chen, Su-Yen; Kuo, Hsin-Yu; Hsieh, T. C. (2019). "New literacy practice in a Facebook group: The case of a residential learning community". Computers \& education, n. 134, pp. 119-131.

https://doi.org/10.1016/j.compedu.2019.01.008

Chen, Xi; Li, Gang; Hu, YunDi; Li, Yujie (2016). "How anonymity influence self-disclosure tendency on Sina Weibo: An empirical study". The anthropologist, v. 26, n. 3, pp. 217-226.

https://doi.org/10.1080/09720073.2016.11892151

Chenavaz, Régis; Drouard, Joeffrey; Escobar, Octavio R.; Karoubi, Bruno (2018). "Convenience pricing in online retailing: Evidence from Amazon.com". Economic modelling, v. 70, pp. 127-139.

https://doi.org/10.1016/j.econmod.2017.10.016

Cheng, Ni; Dong, Ke (2018). "Knowledge communication on social media: a case study of Biomedical Science on Baidu Baike". Scientometrics, v. 116, n. 3, pp. 1749-1770.

https://doi.org/10.1007/s11192-018-2828-1

Chi, Ed H. (2008). "The social web: Research and opportunities". Computer, v. 41, n. 9, pp. 88-91. https://doi.org/10.1109/MC.2008.401

Chua, Alton Y. K.; Banerjee, Snehasish (2017). "Analyzing review efficacy on Amazon. com: Does the rich grow richer?". Computers in human behavior, n. 75, pp. 501-509.

https://doi.org/10.1016/j.chb.2017.05.047 
Coursaris, Constantinos K.; Van-Osch, Wietske (2014). "A scientometric analysis of social media research (2004-2011)". Scientometrics, v. 101, n. 1, pp. 357-380.

https://doi.org/10.1007/s11192-014-1399-z

Cummings, Robert; DiLauro, Frances (2017). "Student perceptions of writing with Wikipedia in Australian higher education". First Monday, v. 22, n. 6.

https://firstmonday.org/ojs/index.php/fm/article/view/7488/6306

Das, Subasish; Dutta, Anandi; Medina, Gabriella; Minjares-Kyle, Lisa; Elgart, Zachary (2019). “Extracting patterns from Twitter to promote biking". IATSS Research, v. 43, n. 1, pp. 51-59.

https://doi.org/10.1016/j.iatssr.2018.09.002

Derakhshan, Adeeb; Lee, Linda; Bhama, Prabhat; Barbarite, Eric; Shaye, David (2019). "Assessing the educational quality of 'YouTube'videos for facelifts". American journal of otolaryngology, v. 40, n. 2, pp. 156-159.

https://doi.org/10.1016/j.amjoto.2019.01.001

De-Veirman, Marijke; Hudders, Liselot (2019). “Disclosing sponsored Instagram posts: the role of material connection with the brand and message-sidedness when disclosing covert advertising". International journal of advertising .

https://doi.org/10.1080/02650487.2019.1575108

De-Vries, Dian A.; Möller, A. Marthe; Wieringa, Marieke S.; Eigenraam, Anniek W.; Hamelink, Kirsten (2018). "Social comparison as the thief of joy: emotional consequences of viewing strangers' Instagram posts". Media psychology, v. 21, n. 2, pp. 222-245.

https://doi.org/10.1080/15213269.2016.1267647

Dong, Chuqing; Rim, Hyejoon (2019). “Exploring nonprofit-business partnerships on Twitter from a network perspective". Public relations review, v. 45, n. 1, pp. 104-118.

https://doi.org/10.1016/j.pubrev.2018.11.001

Dong, Miaomiao; Chen, Ling; Wang, Liwen (2019). "Investigating the user behaviors of sharing health-and fitness-related information generated by Mi Band on Weibo". International journal of human-computer interaction, v. 35, n. 9, pp. 773-786. https://doi.org/10.1080/10447318.2018.1496968

Dupont, Tyler (in press). "Authentic subcultural identities and social media: American skateboarders and Instagram". Deviant behavior,

https://doi.org/10.1080/01639625.2019.1585413

Dutton, William H.; Reisdorf, Bianca C. (2019). "Cultural divides and digital inequalities: attitudes shaping Internet and social media divides". Information, communication \& society, v. 22, n. 1, pp. 18-38.

https://doi.org/10.1080/1369118X.2017.1353640

Edgerly, Stephanie; Vraga, Emily K. (2019). "The blue check of credibility: Does account verification matter when evaluating news on Twitter?". Cyberpsychology, behavior, and social networking, v. 22, n. 4, pp. 283-287.

https://doi.org/10.1089/cyber.2018.0475

Elsevier (2013). International comparative performance of the UK research base - 2013.

https://www.gov.uk/government/publications/performance-of-the-uk-research-baseinternational-comparison-2013

Fairclough, Ruth; Thelwall, Mike (2015). "National research impact indicators from Mendeley readers". Journal of informetrics, v. 9, n. 4, pp. 845-859.

https://doi.org/10.1016/j.joi.2015.08.003

Feng, Debing; Wu, Xiaoping (2018). "Weibo interaction in the discourse of internet anti-corruption: The case of 'Brother Watch' event". Discourse, context \& media, v. 24, n. 1, pp. 99-108.

https://doi.org/10.1016/j.dcm.2018.02.002

Feng, Yang; Xie, Quan (2019). "Demystifying novelty effects: An analysis of consumer responses to YouTube videos featuring augmented reality out-of-home advertising campaigns". Journal of current issues \& research in advertising, v. 40, n. 1, pp. 36-53.

https://doi.org/10.1080/10641734.2018.1500321

Figueroa, Alejandro; Gómez-Pantoja, Carlos; Neumann, Günter (2019). "Integrating heterogeneous sources for predicting question temporal anchors across Yahoo! Answers". Information fusion, v. 50, pp. 112-125.

https://doi.org/10.1016/j.inffus.2018.10.006

Ford, Heather; Wajcman, Judy (2017). "'Anyone can edit', not everyone does: Wikipedia's infrastructure and the gender gap". Social studies of science, v. 47, n. 4, pp. 511-527.

https://doi.org/10.1177/0306312717692172 
Fu, Jiawei-Sophia; Lee, Alice Y. L. (2016). “Chinese journalists' discursive Weibo practices in an extended journalistic sphere". Journalism studies, v. 17, n. 1, pp. 80-99.

https://doi.org/10.1080/1461670X.2014.962927

Gabarrón, Elia; Fernández-Luque, Luis; Armayones, Manuel; Lau, Annie Y. S. (2013). "Identifying measures used for assessing quality of YouTube videos with patient health information: a review of current literature". Interactive journal of medical research, v. 2, n. 1, e6.

https://doi.org/10.2196/ijmr.2465

Gan, Chunmei (2018). "Gratifications for using social media: A comparative analysis of Sina Weibo and WeChat in China". Information development, v. 34, n. 2, pp. 139-147.

https://doi.org/10.1177/0266666916679717

Gauthier, Maude; Sawchuk, Kim (2017). "Not notable enough: feminism and expertise in Wikipedia”. Communication and critical/cultural studies, v. 14, n. 4, pp. 385-402.

https://doi.org/10.1080/14791420.2017.1386321

Geiß, Stefan; Leidecker, Melanie; Roessing, Thomas (2016). "The interplay between media-for-monitoring and media-for-searching: How news media trigger searches and edits in Wikipedia". New media \& society, v. 18, n. 11, pp. 2740-2759.

https://doi.org/10.1177/2F1461444815600281

Gokcen, H. Bahadir; Gumussuyu, Gurkan (2019). "A quality analysis of disc herniation videos on YouTube". World neurosurgery, v. 124, April, e799-e804.

https://doi.org/10.1016/j.wneu.2019.01.146

Grace, Arianne N.; Mueller, Thomas S. (2019). “Gender bias in sport media: a critical analysis of Twitter content and the National Football League's Carolina Panthers". Journal of gender studies, v. 28, n. 3, pp. 363-370.

https://doi.org/10.1080/09589236.2019.1568012

Graminius, Carin; Haider, Jutta (2018). “Air pollution online: everyday environmental information on the social media site Sina Weibo". Journal of documentation, v. 74, n. 4, pp. 722-740.

https://doi.org/10.1108/JD-01-2018-0003

Gupta, Brij-Mohan; Dhawan, Surinder M.; Gupta, Ritu (2015). "Social media research: A scientometric assessment of world publications output during 2001-2014". Journal of scientometric research, v. 4, n. 3, pp. 161-171.

https://doi.org/10.4103/2320-0057.174865

Gupta, Himanshu; Lam, Tina; Pettigrew, Simone; Tait, Robert J. (2019). “A cross-national comparison of the Twitter feeds of popular alcohol brands in India and Australia". Drugs: Education, prevention and policy, v. 26, n. 2, pp. 148-156. https://doi.org/10.1080/09687637.2017.1411886

Hadgkiss, Melissa; Morris, Sarah; Paget, Stacey (2019). "Sifting through the ashes: Amazon Fire TV stick acquisition and analysis". Digital investigation, v. 28, n. 1, pp. 112-118.

https://doi.org/10.1016/j.diin.2019.01.003

Han, Min-Chung; Kim, Youjeong (2017). "Why consumers hesitate to shop online: Perceived risk and product involvement on Taobao.com". Journal of promotion management, v. 23, n. 1, pp. 24-44.

https://doi.org/10.1080/10496491.2016.1251530

Han, Xi; Li, Bei; Qu, Jiabin; Zhu, Qinghua (2018). "Weibo friends with benefits for people live with HIV/AIDS? The implications of Weibo use for enacted social support, perceived social support and health outcomes". Social science \& medicine, v. 211, n. 1, pp. 157-163.

https://doi.org/10.1016/j.socscimed.2018.06.016

Hara, Noriko; Shachaf, Pnina; Hew, Khe-Foon (2010). "Cross-cultural analysis of the Wikipedia community". Journal of the American Society for Information Science and Technology, v. 61, n. 10, pp. 2097-2108.

https://dl.acm.org/toc/jasist/2010/61/10

Hartelius, E. Johanna (2010). "Wikipedia and the emergence of dialogic expertise". Southern communication journal, v. 75, n. 5, pp. 505-526.

https://doi.org/10.1080/10417940903377169

Heilman, James M.; Kemmann, Eckhard; Bonert, Michael; Chatterjee, Anwesh; Ragar, Brent; Beards, Graham M.; Iberri, David J.; Harvey, Matthew; Thomas, Brendan; Stomp, Wouter; Martone, Michael F.; Lodge, Daniel J.; Vondracek, Andrea; De-Wolff, Jacob F.; Liber, Casimir; Grover, Samir C.; Vickers, Tim J.; Meskó, Bertalan; Laurent, Michaël (2011). "Wikipedia: a key tool for global public health promotion". Journal of medical internet research, v. 13, n. 1, e14.

https://www.jmir.org/2011/1/e14 
Hertzum, Morten; Borlund, Pia (2017). “Music questions in social Q\&A: an analysis of Yahoo! Answers". Journal of documentation, v. 73, n. 5, pp. 992-1009.

https://doi.org/10.1108/JD-02-2017-0024

Hino, Airo; Fahey, Robert A. (2019). "Representing the Twittersphere: Archiving a representative sample of Twitter data under resource constraints". International journal of information management, v. 48, pp. 175-184.

https://doi.org/10.1016/j.ijinfomgt.2019.01.019

Holiday, Steven; Anderson, Harper D.; Lewis, Matthew J.; Nielsen, Rachel C. (2019). "'You are what you are in this world': visual framing and exemplification in media coverage of the Guttenfelder Instagram photographs from North Korea". Visual communication, v. 18, n. 2, pp. 231-250.

https://doi.org/10.1177/1470357217739336

Hotez, Peter J.; Molyneux, David H.; Fenwick, Alan; Kumaresan, Jacob; Sachs, Sonia-Ehrlich; Sachs, Jeffrey D.; Savioli, Lorenzo (2007). “Control of neglected tropical diseases”. New England journal of medicine, v. 357, n. 10, pp. 1018-1027. https://doi.org/10.1056/NEJMra064142

Huang, Hong; Chu, Samuel-Kai-Wah; Liu, Lesley-Yuyang; Zheng, Philip-Yi (2017). “Understanding user-librarian interaction types in academic library microblogging: A comparison study in Twitter and Weibo". The journal of academic librarianship, v. 43, n. 4, pp. 329-336.

https://doi.org/10.1016/j.acalib.2017.06.002

Huang, Ran; Kim, HaeJung; Kim, Jiyoung (2013). "Social capital in QQ China: Impacts on virtual engagement of information seeking, interaction sharing, knowledge creating, and purchasing intention". Journal of marketing management, v. 29, n. 3-4, pp. 292-316.

https://doi.org/10.1080/0267257X.2013.766630

Huang, Ronggui; Gui, Yong; Sun, Xiaoyi (2019). "Beyond the left-right spectrum: a typological analysis of ideologues in China's Weibo space". Journal of contemporary China, v. 28, n. 119, pp. 831-847.

https://doi.org/10.1080/10670564.2019.1580423

Hunsinger, Jeremy (2005). "Toward a transdisciplinary internet research". The information society, v. 21, n. 4, pp. 277279.

https://doi.org/10.1080/01972240500189216

Iannone, Alejandra-Emilia (2019). "Ballet education for the web 2.0 generation: a case for using YouTube to teach elementary-school-aged ballet students". International journal of technoethics, v. 10, n. 1, pp. 37-48.

https://doi.org/10.4018/IJT.2019010104

Inan-Eroglu, Elif; Buyuktuncer, Zehra (2018). "What images and content do professional dietitians share via Instagram?". Nutrition \& food science, v. 48, n. 6, pp. 940-948.

https://doi.org/10.1108/NFS-03-2018-0087

Jagiello, Zuzanna A.; Dyderski, Marcin K.; Dylewski, Łukasz (2019). "What can we learn about the behaviour of red and grey squirrels from YouTube?". Ecological informatics, v. 51, pp. 52-60.

https://doi.org/10.1016/j.ecoinf.2019.02.006

Jansen, Bernard J.; Spink, Amanda; Saracevic, Tefko (2000). "Real life, real users, and real needs: a study and analysis of user queries on the web". Information processing \& management, v. 36, n. 2, pp. 207-227.

https://doi.org/10.1016/S0306-4573(99)00056-4

Jiang, Min (2014). "Search concentration, bias, and parochialism: A comparative study of Google, Baidu, and Jike's search results from China". Journal of communication, v. 64, n. 6, pp. 1088-1110.

https://doi.org/10.1111/jcom.12126

Jiang, Yuqin; Li, Zhenlong; Ye, Xinyue (2019). "Understanding demographic and socioeconomic biases of geotagged Twitter users at the county level". Cartography and geographic information science, v. 46, n. 3, pp. 228-242. https://doi.org/10.1080/15230406.2018.1434834

Johnson, Kaprea F.; Worth, Allison; Brookover, Dana (2019). “Families facing the opioid crisis: Content and frame analysis of YouTube videos". The family journal, v. 27, n. 2, pp. 209-220.

https://doi.org/10.1177/1066480719832507

Kaynak, Yurdaer; Kaya, Coskun; Aykaç, Aykut (in press). "YouTube as a source of premature ejaculation". Revista internacional de andrología.

https://doi.org/10.1016/j.androl.2018.12.002 
Konstantopoulou, Anastasia; Rizomyliotis, loannis; Konstantoulaki, Kleopatra; Badahdah, Raghad (2018). “Improving SMEs' competitiveness with the use of Instagram influencer advertising and eWOM". International journal of organizational analysis, v. 27, n. 2, pp. 308-321.

https://doi.org/10.1108/IJOA-04-2018-1406

Kousha, Kayvan; Thelwall, Mike (2017). "Are Wikipedia citations important evidence of the impact of scholarly articles and books?". Journal of the Association for Information Science and Technology, v. 68, n. 3, pp. 762-779.

https://doi.org/10.1002/asi.23694

Kousha, Kayvan; Thelwall, Mike; Abdoli, Mahshid (2012). "The role of online videos in research communication: A content analysis of YouTube videos cited in academic publications". Journal of the Society for Information Science and Technology, v. 63, n. 9, pp. 1710-1727.

https://doi.org/10.1002/asi.22717

Kowalewski, Piotr K.; Olszewski, Robert; Kwiatkowski, Andrzej; Gałązka-Świderek, Natalia; Cichoń, Krzysztof; Paśnik, Krzysztof (2017). "Life with a gastric band. Long-term outcomes of laparoscopic adjustable gastric banding - a retrospective study". Obesity surgery, v. 27, n. 5, pp. 1250-1253.

https://doi.org/10.1007/s11695-016-2435-2

Kuhzady, Salar; Ghasemi, Vahid (2019). "Pictorial analysis of the projected destination image: Portugal on Instagram". Tourism analysis, v. 24, n. 1, pp. 43-54.

https://doi.org/10.3727/108354219X15458295631954

Kwon, K. Hazel (2019). "Public referral, viral campaign, and celebrity participation: a social network analysis of the Ice Bucket Challenge on YouTube". Journal of interactive advertising, v. 19, n. 2, pp. 87-99.

https://doi.org/10.1080/15252019.2018.1561342

Lacatus, Corina (2019). "Populism and the 2016 American election: Evidence from official press releases and Twitter". PS: Political science \& politics, v. 52, n. 2, pp. 223-228.

https://doi.org/10.1017/S104909651800183X

Laestadius, Linnea I.; Wahl, Megan M.; Pokhrel, Pallav; Cho, Young I. (2019). “From Apple to Werewolf: A content analysis of marketing for e-liquids on Instagram". Addictive behaviors, n. 91, pp. 119-127.

https://doi.org/10.1016/j.addbeh.2018.09.008

Lam, Ernest-Tak-Hei; Au, Cheuk-Hang; Chiu, Dickson K. W. (2019). “Analyzing the use of Facebook among university libraries in Hong Kong". The journal of academic librarianship, v. 45, n. 3, pp. 175-183.

https://doi.org/10.1016/j.acalib.2019.02.007

Lee, Eunji; Choi, Tae-Rang; Lee, Taejun; Sung, Yongjun (2019). “Using Instagram while 'in a Relationship': The roles of narcissism and self-esteem". Journal of individual differences, v. 40, n. 2, pp. 111-117.

https://doi.org/10.1027/1614-0001/a000282

Lee, Sang-Gun; Trimi, Silvana; Yang, Chang-Gyu (2018). "Perceived usefulness factors of online reviews: a study of Amazon.com". Journal of computer information systems, v. 58, n. 4, pp. 344-352.

https://doi.org/10.1080/08874417.2016.1275954

Leithner, Andreas; Maurer-Ertl, Werner; Glehr, Mathias; Friesenbichler, Joerg; Leithner, Katharina; Windhager, Reinhard (2010). "Wikipedia and osteosarcoma: a trustworthy patients' information?". Journal of the American Medical Informatics Association, v. 17, n. 4, pp. 373-374.

https://doi.org/10.1136/jamia.2010.004507

Li, Chaoyuan; Wu, Doreen-Dongying (2018). "Facework by global brands across Twitter and Weibo". Discourse, context \& media, v. 26, n. 1, pp. 32-42.

https://doi.org/10.1016/j.dcm.2018.03.006

Li, Kang; Liu, Meiliang; Feng, Yi; Ning, Chuanyi; Ou, Weidong; Sun, Jia; Wei, Wudi; Liang, Hao; Shao, Yiming (2019). "Using Baidu search engine to monitor AIDS epidemics inform for targeted intervention of HIV/AIDS in China". Scientific reports, n. 9, article 320.

https://doi.org/10.1038/s41598-018-35685-w

Li, Li; Lin, Trisha T. C. (2016). “Examining Weibo posting anxiety among well-educated youth in China: A qualitative approach". Information development, v. 32, n. 4, pp. 1240-1252.

https://doi.org/10.1177/0266666915596057

Li, Shu-Chu-Sarrina (2017). "Replacement or complement: A niche analysis of Yahoo news, television news, and electronic news". Telematics and informatics, v. 34, n. 4, pp. 261-273.

https://doi.org/10.1016/j.tele.2016.07.003 
Ling, Wang; Marujo, Luis; Dyer, Chris; Black, Alan W.; Trancoso, Isabel (2016). "Mining parallel corpora from Sina Weibo and Twitter". Computational linguistics, v. 42, n. 2, pp. 307-343.

https://doi.org/10.1162/COLI_a_00249

Liu, Jie; Fu, Xiaodong; Liu, Jin; Sun, Yunchuan (in press). "Analyzing and assessing reviews on JD.com". Intelligent automation \& soft computing.

https://doi.org/10.1080/10798587.2016.1267244

Liu, Weishu; Hu, Guangyuan; Tang, Li; Wang, Yuandi (2015). “China's global growth in social science research: Uncovering evidence from bibliometric analyses of SSCI publications (1978-2013)". Journal of informetrics, v. 9, n. 3, pp. 555-569. https://doi.org/10.1016/j.joi.2015.05.007

Liu, Xinchuan; Lu, Jia; Wang, Haiyan (2017). "When health information meets social media: exploring virality on Sina Weibo". Health communication, v. 32, n. 10, pp. 1252-1260.

https://doi.org/10.1080/10410236.2016.1217454

Liu, Xiaojun; Hu, Wei (2019). "Attention and sentiment of Chinese public toward green buildings based on Sina Weibo". Sustainable cities and society, n. 44, pp. 550-558.

https://doi.org/10.1016/j.scs.2018.10.047

Lloyd, Sian; Osborne, Lisa A.; Reed, Phil (2019). "Personal experiences disclosed by parents of children with autism spectrum disorder: A YouTube analysis". Research in autism spectrum disorders, v. 64, n. 1, pp. 13-22.

https://doi.org/10.1016/j.rasd.2019.03.009

Loeb, Stacy; Sengupta, Shomik; Butaney, Mohit; Macaluso Jr, Joseph N.; Czarniecki, Stefan W.; Robbins, Rebecca; Braithwaite, R. Scott; Gao, Lingshan; Byrne, Nataliya; Walter, Dawn; Langford, Aisha (2019). “Dissemination of misinformative and biased information about prostate cancer on YouTube". European urology, v. 75, n. 4, pp. 564-567.

https://doi.org/10.1016/j.eururo.2018.10.056

Lorigo, Lori; Pan, Bing; Hembrooke, Helene; Joachims, Thorsten; Granka, Laura; Gay, Geri (2006). "The influence of task and gender on search and evaluation behavior using Google". Information processing \& management, v. 42, n. 4, pp. $1123-1131$. https://doi.org/10.1016/j.ipm.2005.10.001

Lui, Debora (2015). "Public curation and private collection: The production of knowledge on Pinterest.com". Critical studies in media communication, v. 32, n. 2, pp. 128-142.

https://doi.org/10.1080/15295036.2015.1023329

Luo, Tian; Xie, Quan (2019). “Using Twitter as a pedagogical tool in two classrooms: a comparative case study between an education and a communication class". Journal of computing in higher education, v. 31, n. 1, pp. 81-104.

https://doi.org/10.1007/s12528-018-9192-2

Luyt, Brendan (2018). "Wikipedia's gaps in coverage: are Wikiprojects a solution? A study of the Cambodian Wikiproject". Online information review, v. 42, n. 2, pp. 238-249.

https://doi.org/10.1108/OIR-06-2017-0199

Ma, Caiwei; Au, Norman (2014). "Social media and learning enhancement among Chinese hospitality and tourism students: A case study on the utilization of Tencent QQ". Journal of teaching in travel \& tourism, v. 14, n. 3, pp. 217-239. https://doi.org/10.1080/15313220.2014.932483

Malik, Aqdas; Li, Yisheng; Karbasian, Habib; Hamari, Juho; Johri, Aditya (2019). “Live, love, Juul: User and content analysis of Twitter posts about Juul". American journal of health behavior, v. 43, n. 2, pp. 326-336.

https://doi.org/10.5993/AJHB.43.2.9

Mao, Yuping; Menchen-Trevino, Ericka (2019). “Global news-making practices on Twitter: Exploring English-Chinese language boundary spanning". Journal of international and intercultural communication, v. 12, n. 3, pp. 248-266.

https://doi.org/10.1080/17513057.2018.1542018

Mariani, Marcello M.; Di-Felice, Marco; Mura, Matteo (2016). "Facebook as a destination marketing tool: Evidence from Italian regional destination management organizations". Tourism management, v. 54, pp. 321-343.

https://doi.org/10.1016/j.tourman.2015.12.008

Marshall, Kayla; Chamberlain, Kerry; Hodgetts, Darrin (2019). “Female bodybuilders on Instagram: Negotiating an empowered femininity". Feminism \& psychology, v. 29, n. 1, pp. 96-119.

https://doi.org/10.1177/0959353518808319

Martín-Quevedo, Juan; Fernández-Gómez, Erika; Segado-Boj, Francisco (2019). “How to engage with younger users on Instagram: A comparative analysis of HBO and Netflix in the Spanish and US markets". International journal on media management, v. 21, n. 2, pp. 67-87.

https://doi.org/10.1080/14241277.2019.1585355 
Mathers, Colin D.; Ezzati, Majid; López, Alan D. (2007). “Measuring the burden of neglected tropical diseases: the global burden of disease framework". PLoS neglected tropical diseases, v. 1, n. 2, e114.

https://doi.org/10.1371/journal.pntd.0000114

Matsuo, Makoto (2015). "Human resource development to facilitate experiential learning: the case of Yahoo Japan". International journal of training and development, v. 19, n. 3, pp. 199-210.

https://doi.org/10.1111/ijtd.12056

McCartney, Glenn; Pek, Rowena-Pao-Cheng (2018). “An examination of Sina Weibo travel blogs' influence on sentiment towards hotel accommodation in Macao". Journal of China tourism research, v. 14, n. 2, pp. 146-157.

https://doi.org/10.1080/19388160.2018.1455614

Meng, Zhaoli; Zuo, Meiyun (2008). "Why MSN lost to QQ in China market? Different privacy protection design". International journal of security and its applications, v. 2, n. 4, pp. 81-88.

https://doi.org/10.1109/ISA.2008.66

Miller, Jordan F. (2019). "YouTube as a site of counternarratives to transnormativity". Journal of homosexuality, v. 66, n. 6, pp. 815-837.

https://doi.org/10.1080/00918369.2018.1484629

Minguillón, Julià; Lerga, Maura; Aibar, Eduard; Lladós-Masllorens, Josep; Meseguer-Artola, Antoni (2017). “Semi-automatic generation of a corpus of Wikipedia articles on science and technology". El profesional de la información, v. 26, n. 5, pp. 995-1004.

https://doi.org/10.3145/epi.2017.sep.20

Mohan, Sriram; Punathambekar, Aswin (2019). "Localizing YouTube: Language, cultural regions, and digital platforms". International journal of cultural studies, v. 22, n. 3, pp. 317-333.

https://doi.org/10.1177/1367877918794681

Mongeon, Philippe; Paul-Hus, Adèle (2016). "The journal coverage of Web of Science and Scopus: a comparative analysis". Scientometrics, v. 106, n. 1, pp. 213-228.

https://doi.org/10.1007/s11192-015-1765-5

Moy, Cheryl L.; Locke, Jonas R.; Coppola, Brian P.; McNeil, Anne J. (2010). “Improving science education and understanding through editing Wikipedia". Journal of chemical education, v. 87, n. 11, pp. 1159-1162.

https://doi.org/10.1021/ed100367v

Munnukka, Juha; Maity, Devdeep; Reinikainen, Hanna; Luoma-aho, Vilma (2019). "'Thanks for watching'. The effectiveness of YouTube vlogendorsements". Computers in human behavior, n. 93, pp. 226-234.

https://doi.org/10.1016/j.chb.2018.12.014

Murthy, Dhiraj; Sharma, Sanjay (2019). "Visualizing YouTube's comment space: online hostility as a networked phenomena". New media \& society, v. 21, n. 1, pp. 191-213.

https://doi.org/10.1177/1461444818792393

Neil, Latisha; Mbilishaka, Afiya (2019). "'Hey curlfriends!': Hair care and self-care messaging on YouTube by black women natural hair vloggers". Journal of black studies, v. 50, n. 2, pp. 156-177.

https://doi.org/10.1177/0021934718819411

Ngai, Cindy S. B.; Jin, Yan (2016). "The effectiveness of crisis communication strategies on Sina Weibo in relation to Chinese publics' acceptance of these strategies". Journal of business and technical communication, v. 30, n. 4, pp. 451-494. https://doi.org/10.1177/1050651916651907

Norris, Benjamin P. (2006). “Google: Its impact on the library". Library hi tech news, v. 23, n. 9, pp. 9-11. https://doi.org/10.1108/07419050610725012

O’Boyle, Jane (2019). "Twitter diplomacy between India and the United States: Agenda-building analysis of tweets during presidential state visits". Global media and communication, v. 15, n. 1, pp. 121-134.

https://doi.org/10.1177/1742766518818859

Ober, Christopher P. (2019). "Twitter in the veterinary diagnostic imaging classroom: examination outcomes and student views". Journal of veterinary medical education, v. 46, n. 1, pp. 91-96.

https://doi.org/10.3138/jvme.0517-069r

Obregón-Sierra, Ángel; González-Fernández, Natalia (2019). "Female university students in the Spanish Wikipedia”. Pixel-bit - Revista de medios y educación, n. 54, pp. 145-164.

https://recyt.fecyt.es/index.php/pixel/article/download/63322/42103 
Ohigashi, An; Ahmed, Salim; Afzal, Arfan R.; Shigeta, Naoko; Tam-Tham, Helen; Kanda, Hideyuki; Ishikawa, Yoshihiro; Turin, Tanvir C. (2017). "Breast cancer information communicated on a public online platform: an analysis of 'Yahoo! Answer Japan'”. Journal of primary health care, v. 9, n. 2, pp. 167-172.

https://doi.org/10.1071/HC16048

Olivares, Nicolás; Vivanco, Luz-María; Figueroa, Alejandro (2018). "The big five: Discovering linguistic characteristics that typify distinct personality traits across Yahoo! Answers Members". Computación y sistemas, v. 22, n. 3, pp. $795-807$. https://www.cys.cic.ipn.mx/ojs/index.php/CyS/article/view/2752

Orttung, Robert W.; Nelson, Elizabeth (2019). "Russia Today's strategy and effectiveness on YouTube". Post-Soviet affairs, v. 35, n. 2, pp. 77-92.

https://doi.org/10.1080/1060586X.2018.1531650

Pathak, Atul-Arun; Bathini, Dharma-Raju; Kandathil, George M. (2015). "The ban on working from home makes sense for Yahoo: It needs the innovation and speed of delivery that come from office-based employees". Human resource management international digest, v. 23, n. 3, pp. 12-14.

https://doi.org/10.1108/HRMID-03-2015-0052

Pérez-López, Faustino R.; Pérez-Roncero, Gonzalo R. (2006). “Assessing the content and quality of information on the treatment of postmenopausal osteoporosis on the World Wide Web". Gynecological endocrinology, v. 22, n. 12, pp. 669-675.

https://doi.org/10.1080/09513590601012603

Polivanova, Katerina; Smirnov, Ivan (2017). "What's in my profile: VKontakte data as a tool for studying the interests of modern teenagers". Voprosy obrazovaniya, n. 2, pp. 134-152.

http://doi.org/10.17323/1814-9545-2017-2-134-152

Pooladian, Aida; Borrego, Ángel (2017). "Methodological issues in measuring citations in Wikipedia: a case study in Library and Information Science". Scientometrics, v. 113, n. 1, pp. 455-464.

https://doi.org/10.1007/s11192-017-2474-z

Qi, Jiaqi; Zheng, Xiaoyong; Guo, Hongdong (2019). "The formation of Taobao villages in China”. China economic review, n. 53 , pp. 106-127.

https://doi.org/10.1016/j.chieco.2018.08.010

Quinn, Fergal; Prendergast, Muireann; Galvin, Audrey (2019). “Her name was Clodagh: Twitter and the news discourse of murder suicide". Critical discourse studies, v. 16, n. 3, pp. 312-329.

https://doi.org/10.1080/17405904.2019.1568896

Rand, Angela-Doucet (2010). "Mediating at the student-Wikipedia intersection". Journal of library administration, v. 50, n. 7-8, pp. 923-932.

https://doi.org/10.1080/01930826.2010.488994

Rangarajan, Karan; Begg, Khalil; Somani, Bhaskar (2019). “Online digital media: The uptake of YouTube-based digital clinical education (DCE)". American journal of distance education, v. 33, n. 2, pp. 142-150.

https://doi.org/10.1080/08923647.2019.1582308

Ray, Santosh-Kumar; Singh, Shailendra; Joshi, Bhagwati P. (2010). "A semantic approach for question classification using WordNet and Wikipedia". Pattern recognition letters, v. 31, n. 13, pp. 1935-1943.

https://doi.org/10.1016/j.patrec.2010.06.012

Rindova, Violina P.; Yeow, Adrian Y. K.; Martins, Luis L.; Faraj, Samer A. (2012). "Partnering portfolios, value-creation logics, and growth trajectories: A comparison of Yahoo and Google (1995 to 2007)". Strategic entrepreneurship journal, v. 6, n. 2, pp. 133-151.

https://doi.org/10.1002/sej.1131

Ritala, Paavo; Golnam, Arash; Wegmann, Alain (2014). "Coopetition-based business models: The case of Amazon.com”. Industrial marketing management, v. 43, n. 2, pp. 236-249.

https://doi.org/10.1016/j.indmarman.2013.11.005

Rodríguez-Mateos, David; Hernández-Pérez, Tony (2018). "Spanish newspapers as a reference source of Wikipedia”. El profesional de la información, v. 27, n. 6, pp. 1323-1333.

https://doi.org/10.3145/epi.2018.nov.15

Rühl, Giesela (2018). "A. Court of Justice The unfairness of choice-of-law clauses, or: The (unclear) relationship between Article 6 Rome I Regulation and the unfair terms in consumer contracts directive: VKI v. Amazon". Common market law review, v. 55, n. 1, pp. 201-224. 
https://www.kluwerlawonline.com/abstract.php?area=Journals\&id=COLA2018007

Rykov, Yuri G.; Koltsova, Olessia Y.; Meylakhs, Peter A. (2016). "Structure and functions of online communities: Network mapping of HIV-relevant groups in VK.com SNS". Sociological studies, v. 8, n. 8, pp. 30-42.

http://socis.isras.ru/en/article/6310

Santarossa, Sara; Coyne, Paige; Lisinski, Carly; Woodruff, Sarah J. (2019). “\#fitspo on Instagram: A mixed-methods approach using Netlytic and photo analysis, uncovering the online discussion and author/image characteristics". Journal of health psychology, v. 24, n. 3, pp. 376-385.

https://doi.org/10.1177/1359105316676334

Segev, Elad; Ahituv, Niv (2010). "Popular searches in Google and Yahoo!: A 'digital divide' in information uses?". The information society, v. 26, n. 1, pp. 17-37.

https://doi.org/10.1080/01972240903423477

Segev, Elad; Sharon, Aviv J. (2017). "Temporal patterns of scientific information-seeking on Google and Wikipedia”. Public understanding of science, v. 26, n. 8, pp. 969-985.

https://doi.org/10.1177/0963662516648565

Shchekoturov, Aleksandr V. (2017). "From flirting to sex reassignment: Adolescents' alternative practices of self-presentation on vkontakte social media website". Monitoring obshchestvennogo mneniya: Ekonomicheskie i sotsial'nye peremeny, v. 6, n. 142, pp. 330-346.

https://wciom.ru/fileadmin/file/monitoring/2017/142/2017_142_17_Shchekoturov.pdf

Shen, Haiying; Li, Ze; Liu, Jinwei; Grant, Joseph-Edward (2015). "Knowledge sharing in the online social network of Yahoo! answers and its implications". IEEE transactions on computers, v. 64, n. 6, pp. 1715-1728.

https://doi.org/10.1109/TC.2014.2322598

Shultz, Ginger V.; Zemke, Jennifer M. (2019). "'I wanna just Google it and find the answer': Student information searching in a problem-based inorganic chemistry laboratory experiment". Journal of chemical education, v. 96, n. 4, pp. 618-628.

https://doi.org/10.1021/acs.jchemed.8b00821

Silver, David (2004). "Internet/cyberculture/digital culture/new media/fill-in-the-blank studies". New media \& society, v. 6, n. 1 , pp. 55-64.

https://doi.org/10.1177/1461444804039915

Simpson, Andrea; Le, Michelle; Malicka, Alicja N. (2018). "The accuracy and readability of Wikipedia articles on hearing loss". Journal of consumer health on the internet, v. 22, n. 4, pp. 323-336.

https://doi.org/10.1080/15398285.2018.1542251

Smith, Brent; Linden, Greg (2017). "Two decades of recommender systems at Amazon.com". IEEE internet computing, v. 21, n. 3, pp. 12-18.

https://doi.ieeecomputersociety.org/10.1109/MIC.2017.72

Smith, Chad E. (2006). "Where is it? How deaf adolescents complete fact-based Internet search tasks". American annals of the deaf, v. 151, n. 5, pp. 519-529.

https://www.jstor.org/stable/26234414

Sohal, Seerat; Kaur, Harsandaldeep (2018). "A content analysis of YouTube political advertisements: evidence from Indian parliamentary elections". Journal of creative communications, v. 13, n. 2, pp. 133-156.

https://doi.org/10.1177/0973258618761408

Spierings, Niels; Jacobs, Kristof; Linders, Nik (2019). "Keeping an eye on the people: Who has access to MPs on Twitter?". Social science computer review, v. 37, n. 2, pp. 160-177.

https://doi.org/10.1177/0894439318763580

Stage, Carsten (2019). “Affective measures: self-measurement and gridding in female cancer patients' storytelling practices on Instagram". Distinktion: Journal of social theory, v. 20, n. 1, pp. 77-100.

https://doi.org/10.1080/1600910X.2019.1580594

Stahel, David (2018). "The battle for Wikipedia: The new age of 'lost victories'?". The journal of Slavic military studies, v. 31, n. 3, pp. 396-402.

https://doi.org/10.1080/13518046.2018.1487198

Stevens, Charles E.; Xie, En; Peng, Mike W. (2016). "Toward a legitimacy-based view of political risk: The case of Google and Yahoo in China". Strategic management journal, v. 37, n. 5, pp. 945-963.

https://doi.org/10.1002/smj.2369 
Tandoc, Edson C.; Cabañes, Jason-Vincent A.; Cayabyab, Ysa M. (2019). “Bridging the gap: Journalists' role orientation and role performance on Twitter". Journalism studies, v. 20, n. 6, pp. 857-871.

https://doi.org/10.1080/1461670X.2018.1463168

Teplitskiy, Misha; Lu, Grace; Duede, Eamon (2017). "Amplifying the impact of open access: Wikipedia and the diffusion of science". Journal of the Association for Information Science and Technology, v. 68, n. 9, pp. 2116-2127.

https://doi.org/10.1002/asi.23687

Thelwall, Mike (2016). "Does astronomy research become too dated for the public? Wikipedia citations to astronomy and astrophysics journal articles 1996-2014". El profesional de la información, v. 25, n. 6, pp. 893-900.

https://doi.org/10.3145/epi.2016.nov.06

Thelwall, Mike (2017). "Three practical field normalised alternative indicator formulae for research evaluation". Journal of informetrics, v. 11, n. 1, pp. 128-151.

https://doi.org/10.1016/j.joi.2016.12.002

Thelwall, Mike; Mas-Bleda, Amalia (2018). "YouTube science channel video presenters and comments: Female friendly or vestiges of sexism?". Aslib journal of information management, v. 70, n. 1, pp. 28-46.

https://doi.org/10.1108/AJIM-09-2017-0204

Thelwall, Mike; Sud, Pardeep (2018). “A comparison of title words for journal articles and Wikipedia pages: Coverage and stylistic differences?". El profesional de la información, v. 27, n. 1, pp. 49-64.

https://doi.org/10.3145/epi.2018.ene.05

Thelwall, Mike; Sud, Pardeep; Vis, Farida (2012). "Commenting on YouTube videos: From Guatemalan rock to El Big Bang". Journal of the Society for Information Science and Technology, v. 63, n. 3, pp. 616-629.

https://doi.org/10.1002/asi.21679

Usher, Nikki; Holcomb, Jesse; Littman, Justin (2018). "Twitter makes it worse: Political journalists, gendered echo chambers, and the amplification of gender bias". The international journal of press/politics, v. 23, n. 3, pp. 324-344.

https://doi.org/10.1177/1940161218781254

Ushkin, Sergey G. (2014). "Consumers' comments on protest actions in the Russian-language YouTube segment". Sociological studies, v. 6, n. 6, pp. 127-133.

Vaughan, Liwen (2012). "An alternative data source for web hyperlink analysis: 'Sites Linking In' at Alexa Internet". Collnet journal of scientometrics and information management, v. 6, n. 1, pp. 31-42.

https://doi.org/10.1080/09737766.2012.10700922

Vaughan, Liwen; Thelwall, Mike (2004). "Search engine coverage bias: evidence and possible causes". Information processing \& management, v. 40, n. 4, pp. 693-707.

https://doi.org/10.1016/S0306-4573(03)00063-3

Vetter, Matthew A.; McDowell, Zachary J.; Stewart, Mahala (2019). "From opportunities to outcomes: the Wikipedia-based writing assignment". Computers and composition, v. 52, n. 1, pp. 53-64.

https://doi.org/10.1016/j.compcom.2019.01.008

Vuori, Juha-Antero; Paltemaa, Lauri (2015). "The lexicon of fear: Chinese internet control practice in Sina Weibo microblog censorship". Surveillance \& society, v. 13, n. 3/4, pp. 400-421.

https://doi.org/10.24908/ss.v13i3/4.5404

Waltman, Ludo; Van-Eck, Nees-Jan; Van-Leeuwen, Thed N.; Visser, Martijn S.; Van-Raan, Anthony F. J. (2011). “Towards a new crown indicator: An empirical analysis". Scientometrics, v. 87, n. 3, pp. 467-481.

https://doi.org/10.1007/s11192-011-0354-5

Wang, Hongyu; Shi, Fayong (2018). "Weibo use and political participation: the mechanism explaining the positive effect of Weibo use on online political participation among college students in contemporary China". Information, communication \& society, v. 21, n. 4, pp. 516-530.

https://doi.org/10.1080/1369118X.2017.1289234

Wang, Nan; Sun, Yongqiang; Shen, Xiao-Liang; Zhang, Xi (2018). "A value-justice model of knowledge integration in wikis: The moderating role of knowledge equivocality". International journal of information management, n. 43, pp. 64-75. https://doi.org/10.1016/j.ijinfomgt.2018.07.006

Wen, Wen; Clark, Melissa; Kang, Bomi; Fine, Monica (2016). "The use of Sina Weibo and Twitter by international luxury hotels". Tourism culture \& communication, v. 16, n. 3, pp. 137-145.

https://doi.org/10.3727/109830416X14750895902837 
Wilson, Tom; Lovelace, Robin; Evans, Andrew J. (2019). "A path toward the use of trail users' tweets to assess effectiveness of the environmental stewardship scheme: an exploratory analysis of the Pennine Way National Trail". Applied spatial analysis and policy, v. 12, n. 1, pp. 71-99.

https://doi.org/10.1007/s12061-016-9201-7

Wu, Xiaoping (2018). "Discursive strategies of resistance on Weibo: A case study of the 2015 Tianjin explosions in China". Discourse, context \& media, v. 26, n. 1, pp. 64-73.

https://doi.org/10.1016/j.dcm.2018.05.002

Xiao, Min; Wang, Rang; Chan-OImsted, Sylvia (2018). "Factors affecting YouTube influencer marketing credibility: a heuristic-systematic model". Journal of media business studies, v. 15, n. 3, pp. 188-213.

https://doi.org/10.1080/16522354.2018.1501146

Xiong, Ying; Cho, Moonhee; Boatwright, Brandon (2019). "Hashtag activism and message frames among social movement organizations: Semantic network analysis and thematic analysis of Twitter during the\# MeToo movement". Public relations review, v. 45, n. 1, pp. 10-23.

https://doi.org/10.1016/j.pubrev.2018.10.014

Yang, Heng-Li; Lai, Cheng-Yu (2010). "Motivations of Wikipedia content contributors". Computers in human behavior, v. 26, n. 6, pp. 1377-1383.

https://doi.org/10.1016/j.chb.2010.04.011

Yau, Joanna C.; Reich, Stephanie M. (2019). “'It's just a lot of work': Adolescents' self-presentation norms and practices on Facebook and Instagram". Journal of research on adolescence, v. 29, n. 1, pp. 196-209.

https://doi.org/10.1111/jora.12376

Yu, Houqiang; Xu, Shenmeng; Xiao, Tingting; Hemminger, Brad M.; Yang, Siluo (2017). "Global science discussed in local altmetrics: Weibo and its comparison with Twitter". Journal of informetrics, v. 11, n. 2, pp. 466-482.

https://doi.org/10.1016/j.joi.2017.02.011

Yuan, Elaine; Feng, Miao; Liu, Xiyuan (2019). "The R/evolution of civic engagement: An exploratory network analysis of the Facebook groups of occupy Chicago". Information, communication \& society, v. 22, n. 2, pp. 267-285.

https://doi.org/10.1080/1369118X.2017.1371786

Yuan, Liuliang; Liu, Wei (2017). "The influence of contextual support on persistent sharing willingness of QQ group members: Mediating effect of autonomous motivations". Online information review, v. 41, n. 2, pp. $185-201$.

https://doi.org/10.1108/OIR-01-2016-0009

Zahedi, Zohreh; Shirazi, Mansooreh-Serati; Dehghani, Leila (2010). “A webometric analysis of ISI medical journals using Yahoo, AltaVista, and All the Web search engines". Iranian journal of information processing and management, v. 26, n. 1, pp. 89-108.

http://jipm.irandoc.ac.ir/article-1-1236-en.html

Zhang, Angela H. (2011). "Using a sledgehammer to crack a nut: Why China's anti-monopoly law was inappropriate for Renren v. Baidu". Competition policy international journal, v. 7, n. 1, pp. 277-298.

https://www.competitionpolicyinternational.com/using-a-sledgehammer-to-crack-a-nut-why-china-s-anti-monopolylaw-was-inapproriate-for-renren-v-baidu

Zhang, Pengyi (2013). "Social Inclusion or exclusion? when Weibo (microblogging) meets the new generation of rural migrant workers". Library trends, v. 62, n. 1, pp. 63-80.

https://doi.org/10.1353/lib.2013.0026

Zhou, Huiquan; Pan, Quanxiao (2016). "Information, community, and action on Sina-Weibo: How Chinese philanthropic NGOs use social media". Voluntas: International journal of voluntary and nonprofit organizations, v. 27, n. 5, pp. 24332457.

https://doi.org/10.1007/s11266-016-9685-4

Zhou, Wenyan; Hinz, Oliver (2016). "Determining profit-optimizing return policies-a two-step approach on data from Taobao.com". Electronic markets, v. 26, n. 2, pp. 103-114.

https://doi.org/10.1007/s12525-015-0198-6

Zhu, Feng; Liu, Qihong (2018). "Competing with complementors: An empirical look at Amazon.com". Strategic management journal, v. 39, n. 10, pp. 2618-2642.

https://doi.org/10.1002/smj.2932 